\title{
Targeting tumor hypoxia and mitochondrial metabolism with anti-parasitic drugs to improve radiation response in high-grade gliomas
}

\author{
Faiqa Mudassar ${ }^{1}$, Han Shen ${ }^{1,2^{*}}$, Geraldine O'Neill ${ }^{3,4,5}$ and Eric Hau ${ }^{1,2,6,7}$
}

\begin{abstract}
High-grade gliomas (HGGs), including glioblastoma and diffuse intrinsic pontine glioma, are amongst the most fatal brain tumors. These tumors are associated with a dismal prognosis with a median survival of less than 15 months. Radiotherapy has been the mainstay of treatment of HGGs for decades; however, pronounced radioresistance is the major obstacle towards the successful radiotherapy treatment. Herein, tumor hypoxia is identified as a significant contributor to the radioresistance of HGGs as oxygenation is critical for the effectiveness of radiotherapy. Hypoxia plays a fundamental role in the aggressive and resistant phenotype of all solid tumors, including HGGs, by upregulating hypoxia-inducible factors (HIFs) which stimulate vital enzymes responsible for cancer survival under hypoxic stress. Since current attempts to target tumor hypoxia focus on reducing oxygen demand of tumor cells by decreasing oxygen consumption rate (OCR), an attractive strategy to achieve this is by inhibiting mitochondrial oxidative phosphorylation, as it could decrease OCR, and increase oxygenation, and could therefore improve the radiation response in HGGs. This approach would also help in eradicating the radioresistant glioma stem cells (GSCs) as these predominantly rely on mitochondrial metabolism for survival. Here, we highlight the potential for repurposing anti-parasitic drugs to abolish tumor hypoxia and induce apoptosis of GSCs. Current literature provides compelling evidence that these drugs (atovaquone, ivermectin, proguanil, mefloquine, and quinacrine) could be effective against cancers by mechanisms including inhibition of mitochondrial metabolism and tumor hypoxia and inducing DNA damage. Therefore, combining these drugs with radiotherapy could potentially enhance the radiosensitivity of HGGs. The reported efficacy of these agents against glioblastomas and their ability to penetrate the blood-brain barrier provides further support towards promising results and clinical translation of these agents for HGGs treatment.
\end{abstract}

Keywords: High-grade gliomas, Radioresistance, Hypoxia, HIFs, Mitochondria, Metabolism, Glioma stem cells, Antiparasitic drugs

\footnotetext{
* Correspondence: han.shen@sydney.edu.au

${ }^{1}$ Translational Radiation Biology and Oncology Laboratory, Centre for Cancer Research, Westmead Institute for Medical Research, NSW, Westmead,

Australia

${ }^{2}$ Sydney Medical School, University of Sydney, NSW, Sydney, Australia

Full list of author information is available at the end of the article
}

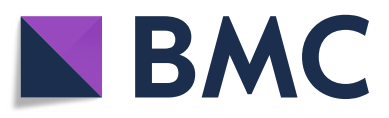

(C) The Author(s). 2021, corrected publication 2021. Open Access This article is licensed under a Creative Commons Attribution 4.0 International License, which permits use, sharing, adaptation, distribution and reproduction in any medium or format, as long as you give appropriate credit to the original author(s) and the source, provide a link to the Creative Commons licence, and indicate if changes were made. The images or other third party material in this article are included in the article's Creative Commons licence, unless indicated otherwise in a credit line to the material. If material is not included in the article's Creative Commons licence and your intended use is not permitted by statutory regulation or exceeds the permitted use, you will need to obtain permission directly from the copyright holder. To view a copy of this licence, visit http://creativecommons.org/ licenses/by/4.0/. The Creative Commons Public Domain Dedication waiver (http://creativecommons.org/publicdomain/zero/1. 0/) applies to the data made available in this article, unless otherwise stated in a credit line to the data. 


\section{Background}

High-grade gliomas (HGGs) are malignant and incurable tumors arising from glial cells, present in the central nervous system (CNS). The World Health Organization (WHO) classifies the HGGs as either grade III or grade IV tumors, based on the histopathological criteria. HGGs can originate in various parts of the CNS and affect individuals of all age groups. Despite advances in treatment modalities, the heterogeneous nature of the tumor accounts for a notoriously poor prognosis and limits the efficacy of conventional therapies [1]. Resistance to chemo- and radiotherapy results in high relapse rates and tumor recurrence, thus posing a significant challenge to the field of oncology. The deadliest of these HGGs is the glioblastoma in adults and diffuse intrinsic pontine glioma (DIPG) in children.

\section{Glioblastoma}

Glioblastoma is the most frequently diagnosed and aggressive tumor of all HGGs. It represents $14.6 \%$ of all primary CNS tumors and $48.3 \%$ of all primary malignant CNS tumors [2]. It is characterized as an anaplastic, poorly differentiated, and highly cellular, grade IV astrocytoma with the peak incidence between 45 and 70 years $[3,4]$. The majority of HGGs $(\sim 95 \%)$ originate in the supratentorial area of the brain and a small proportion arise in the brainstem, spinal cord and cerebellum [5]. Despite optimal treatment, the median survival of glioblastomas is only 9-15 months, and the 5-year survival is $6.8 \%$; thus, contributing to the significant social and medical health burden $[2,6]$.

Surgery is the primary standard of care for glioblastoma patients [7]. However, the infiltrative nature of glioblastoma means that it cannot be cured by surgery alone and approximately $80 \%$ of the tumors relapse within $2-3 \mathrm{~cm}$ margin of the pre-surgical lesion $[3,8]$. Surgical resection is generally followed by radiotherapy, along with concomitant or adjuvant temozolomide (TMZ), an oral alkylating agent $[3,6]$. The combination of radiation plus TMZ offers a modest survival advantage of 2.5 months only (14.6 months for combination treatment vs. 12.1 months for radiotherapy alone) and improving clinical outcomes in glioblastoma remains a challenge [9]. Moreover, despite decades of clinical research and investigating novel chemotherapeutic agents, glioblastoma remains incurable due to the complex nature of the tumor and intratumoral heterogeneity [8]. Radiotherapy remains the cornerstone of treatment for most glioblastoma patients [10], particularly where TMZ chemotherapy efficacy is limited. However, the intrinsic or acquired radioresistance of glioblastoma contribute to local tumor recurrence, thus limiting the effectiveness of radiotherapy [3].

\section{Diffuse Intrinsic Pontine Glioma}

DIPG is a deadly form of HGG primarily affecting children. It represents $10-20 \%$ of all childhood brain malignancies and accounts for the majority of brain cancer-related deaths in children [11]. DIPG originates in the pons of the children and has a peak incidence between 6 and 9 years [11]. It is a fatal tumor as patients survive on average for only 8-12 months, with a subsequent increase in the mortality rate of $70 \%$ at one year, $90 \%$ at two years and $>99 \%$ at five years following diagnosis $[12,13]$.

As a result of the sensitive brainstem location and invasiveness of the tumor, DIPGs are not amenable to surgical resection [14]. Currently, radiotherapy is the only efficacious treatment available for prolonging patient survival $[11,15]$. However, the effect of radiotherapy in controlling tumor size is temporary, and survival is only prolonged for approximately three months [16]. Symptoms of disease progression inevitably reappear 3-8 months following completion of radiotherapy [16]. Various chemotherapeutic agents, including TMZ, Bevacizumab (VEGF inhibitor) and EGFR inhibitors, have been investigated either alone or combined with radiation to improve patient prognosis $[14,17,18]$. Unfortunately, all the aforementioned strategies have been unsuccessful in improving the overall survival of DIPG patients over radiotherapy alone. The lack of efficacy of chemotherapy drugs might be as a consequence of the intrinsic resistance of DIPG to these drugs, or lack of ability of the drugs to penetrate the intact blood-brain barrier (BBB) $[15,19]$. Other factors affecting the ability to deliver drug at sufficient concentration in DIPG include drug bioavailability, i.e. the serum levels and protein/tissue binding, blood flow to the pons, and the drug metabolism [14, 15].

Since all HGGs, including glioblastoma and DIPG, recur following treatment, there is an increasing need to develop new treatments in developing a cure for these deadly malignancies. Radiotherapy has been the mainstay of treatment for all malignant gliomas and has been the only standard treatment for DIPG for decades [1, 12]. However, after the completion of radiotherapy, almost all HGGs relapse secondary to radioresistance. Therefore, improving the effectiveness of radiotherapy and overcoming radioresistance remain the most promising approach to improve the patient survival outcomes. Understanding the mechanisms of radioresistance in HGGs may provide insight into ways to enhance the radiosensitivity of tumor cells and increase the efficacy of radiotherapy.

This review aims to outline mechanisms responsible for radioresistance in HGGs, particularly in glioblastoma and DIPG, with an emphasis on the role of hypoxia and the associated metabolic pathways implicated in tumor recurrence, metastasis, and resistance to chemo- and radiotherapy. It will address how inhibiting mitochondrial metabolism is an attractive strategy to decrease tumor hypoxia and increase oxygenation and therefore radiosensitize the tumor cells. It further discusses the need for mitochondrial targeted therapies against the resistant glioma stem 
cells (GSCs) which are significant contributors to tumor recurrence and relapse. Finally, it poses repurposing antiparasitic drugs in combination with radiotherapy as an approach to abolish tumor hypoxia and eradicate both GSCs and glioma differentiated cells, and therefore offer an approach to improve radiotherapy efficacy.

\section{Hypoxia and Radioresistance}

Cancer cells have various mechanisms to escape cell death via radiotherapy. Some of these mechanisms include, the ability of cancer cells to repair the radiationinduced DNA damage; cell-cycle arrest; alterations in the expression of oncogenes and tumor suppressor genes; autophagy induction; variations in tumor microenvironment such as hypoxia, elevation in cytokine levels, and epithelial to mesenchymal transitions; generation of cancer stem cells (CSCs); and alterations in tumor metabolism [20]. Of these, the development of tumor hypoxia and the associated metabolic pathways is one of the most important contributors to clinical radioresistance [21]. Hypoxia, a state which deprives the tissue of adequate oxygen supply, is a common microenvironment feature of almost all solid tumors [22]. Hypoxia is a pathophysiological condition that generally arises as a consequence of the rapid proliferation of cancer cells as they outgrow their blood supply, therefore depleting the cells of nutrients and available oxygen [22]. Hypoxic tumors are found to be highly aggressive, resistant to chemo- and radiotherapy, and associated with poor patient prognosis [23]. The hypoxic microenvironment poses a significant barrier and impedes the clinical outcome of radiotherapy as hypoxic tumors require triple the normal radiation dose to achieve the desirable cell death effect as irradiating normoxic tumors [24]. This indicates that tumor hypoxia substantially diminishes the efficacy of conventional anti-cancer approaches.

The link between hypoxia and radiation resistance was first established in the 1950s by Gray and his colleagues, who demonstrated that hypoxia caused radiation resistance in various plant, microbes and malignant mammalian tissues [25]. Ionizing radiation induces a chemical change and damages DNA by inducing free radicals [26]. Oxygen reacts with these free radicals, forming oxygen peroxide which "fix" the radiation-induced DNA damage, thus inducing permanent DNA damage [26]. As a consequence of the free radicals generated by radiation, an enormous amount of cytotoxic reactive oxygen species (ROS) are generated that interact with the DNA and cause further damage, leading to cell death [26]. However, under hypoxic conditions, DNA free radicals can restore back to their original form due to low oxygen levels, and irreversible DNA damage does not occur, thus compromising the radiation-induced DNA damage in the hypoxic tumor cells.

\section{Evidence of Hypoxia in HGGs}

Hypoxia is associated with malignant progression, therapy resistance, and poor prognosis of glioblastomas [27, 28]. Previous research has provided experimental evidence of the presence of hypoxia in human gliomas [29, 30]. By utilizing an Eppendorf needle electrode, studies have revealed that oxygenation in glioblastoma drops to $10 \mathrm{mmHg}$ compared to $40 \mathrm{mmHg}$ in normal brain tissue $[29,30]$. This provided solid support towards the underlying hypoxic radioresistance in gliomas which generally arises when oxygen levels in tumors drop to $\sim 0$ $10 \mathrm{mmHg}$ [30]. The close relationship between between hypoxia and radioresistance in gliomas has been noted in a number of studies [31-34].

A wide range of imaging approaches have been developed to understand the dynamics between oxygenation and hypoxia in gliomas, with positron emission tomography (PET) using ${ }^{18} \mathrm{~F}$-fluoromisonidazole (FMISO) being the current gold standard for hypoxia imaging [27]. Using FMISO PET, Spence et al. 2008 showed that the volume and intensity of hypoxia in glioblastoma was associated with a poor time to tumor progression and reduced survival [35]. This identification of hypoxic regions in tumors could help in the design of modified dosages of radiotherapy or chemotherapeutics and therefore improve clinical outcomes [36].

Similarly, studies have also provided evidence of the possible link between hypoxia and pediatric HGGs and DIPG $[37,38]$. Recently, Yeom et al. 2015 used proton magnetic resonance spectroscopy and identified high levels of citrate in DIPG patients which was correlated with poor tissue perfusion [38]. An increase in citrate, a metabolic byproduct of the tricarboxylic acid (TCA) cycle has been previously observed in animal studies during hypoxic conditions [39]. Since tumor hypoxia relates to a decrease in blood supply, the hypoperfusion observed indicates that DIPGs are hypoxic tumors [38]. This hypoxic nature is the critical factor in conferring radioresistance to DIPGs [38]. Therefore, understanding the hypoxic mechanisms in cancers is crucial in order to derive strategies to target tumor hypoxia and improve the radiation response in HGGs.

\section{Role of Hypoxia and Mitochondrial Metabolism in Cancer Progression} Hypoxia and HIFs

During hypoxic conditions, cancer cells upregulate crucial metabolic enzymes that help them adapt to the demand for nutrients and changes in their redox status. Adaptation to the hypoxic environment is partly mediated by the activation and stabilization of transcription factors termed as a hypoxia-inducible factors (HIFs) via inactivation of HIF propyl hydroxylases (PHD) [40]. HIFs comprise three isoforms with oxygen-labile $\alpha$ subunits (HIF-1 $\alpha$, HIF- $2 \alpha$, HIF-3 $\alpha$ ) that are involved in the 
adaptation to hypoxic stress, and a stable $\beta$ subunit. Of these, HIF- $1 \alpha$ is found to be constitutively expressed in many tumor cells, whereas the expression of HIF- $2 \alpha$ and HIF- $3 \alpha$ is restricted to certain tissues only. Under normoxia, HIF- $\alpha$ is stabilized via hydroxylation by PHDs, and undergoes ubiquitylation by binding to the tumor suppressor von Hippel-Lindau protein (pVHL), resulting in proteasomal degradation of the $\alpha$ subunit [40]. However, these HIFs are no longer degraded under hypoxia and instead, hypoxia causes HIFs to dimerize and bind to the hypoxia-responsive elements, thereby driving transcription of various genes vital for cancer cell survival, metabolism, angiogenesis, $\mathrm{pH}$ homeostasis, and metastasis [22]. Hypoxia dependent stabilization of HIFs is found to enhance tumor progression, metastatic dissemination, and maintain the intrinsically radioresistant GSC population [31, 32]. Hypoxia may sustain radioresistance of gliomas, and therefore targeting tumor hypoxia by inhibiting HIF- $1 \alpha$ could enhance the radiosensitivity of human malignant gliomas and subsequently improve the radiotherapy outcomes [33, 34]. Moreover, hypoxia and HIFs overexpression in tumors is also correlated with increased risk of mortality [41].

\section{HIFs - Driver of Aerobic Glycolysis}

The metabolic requirements of normal healthy cells are considerably different from rapidly proliferating cancer cells. As opposed to normal cells that primarily depend upon the mitochondrial oxidative phosphorylation (OXPHOS) for energy production, most cancer cells preferentially use the aerobic glycolysis, converting glucose into lactic acid, even with enough available oxygen. Known as the Warburg effect, this results in abnormal proliferation of cancer cells and facilitates malignant progression [42]. The hypoxia induced transcription factors - HIFs, play a key role in driving cancer cells towards the glycolytic phenotype (Fig. 1) [42].

During aerobic glycolysis, the glucose converted into pyruvate is reduced to lactate within the cytoplasm, instead of undergoing OXPHOS in the mitochondria [22]. This response is mediated via HIF- $1 \alpha$ driven gene expression of two metabolic enzymes - lactate dehydrogenase A (LDH-A) and pyruvate dehydrogenase kinase 1 (PDK1) [22]. LDH-A is vital in the conversion of pyruvate into lactate, and PDK1 inactivates pyruvate dehydrogenase (PDH) and subsequently prevents pyruvate oxidation in the mitochondria [22]. HIF-1 $\alpha$ also controls lactate efflux via specialized monocarboxylate transporter - 4 (MCT4), as lactate production decreases cellular $\mathrm{pH}$ and is therefore toxic to cancer cells [43]. Hence, hypoxia and HIF-1 $\alpha$ increase glucose channeling into glycolysis while suppressing OXPHOS and mitochondrial respiration by decreasing the input into mitochondria (Fig. 1) [44]. Gliomas are also found to preferentially rely on glycolysis and produce high concentrations of lactate [45]. The malignant phenotype of cancer cells is therefore supported by enhanced glycolytic rate, lactate production and excretion of lactate, resulting in extracellular acidification.

\section{Lactate - Signaling Molecule for Tumorigenesis}

The production of large quantities of lactate as a byproduct of glycolysis plays a pivotal role in regulating cancer phenotypes such as cancer cell migration, angiogenesis, metastasis, and immunosuppression [43]. Studies have demonstrated that lactate stimulates angiogenesis via HIF-1 mediated upregulation of the angiogenic growth factor and its receptor - VEGF and VEGFR2 by endothelial and tumor cells $[46,47]$. Vegran et al. 2011 reported that lactate also modulates angiogenesis independent of HIFs by promoting NF- $\mathrm{kB} / \mathrm{IL}-8$ signaling [48]. Moreover, lactate also binds to N-MYC downstream regulatory gene 3 (NDRG3), which is highly induced under hypoxia and activates Raf-ERK pathway signaling, therefore promoting angiogenesis [49]. Extracellular lactate accumulation also promotes cancer cell migration by facilitating the interaction of CD44 and hyaluronic acid action on fibroblasts, therefore regulating cell adhesion, motility, and proliferation [50]. Interestingly, lactate also confers a survival advantage on cancer cells by enabling cells to escape immune surveillance [51]. This mainly occurs as lactate drives apoptosis of the cytotoxic $\mathrm{T}$ cells and natural killer (NK) cells and enhances the proliferation of myeloidderived suppressor, cells which further decrease NK and T cell activity [51].

\section{Mitochondrial Biogenesis and Oxidative Phosphorylation in Cancers}

An enhanced rate of aerobic glycolysis suggests that cancer cells should have a decreased rate of OXPHOS; however, current research increasingly suggests that along with glycolysis, some cancers also rely on mitochondrial biogenesis and OXPHOS for energy production and in vivo progression $[52,53]$. The aforementioned is supported by the notion that cancer cells display high metabolic plasticity and can alter their metabolic phenotypes under various selection pressures [53]. A recent study by Shen et al. 2020 reported that although pediatric HGGs exhibit a glycolytic phenotype with reduced reliance on mitochondrial OXPHOS, inhibition of glycolysis by PDK1 inhibitor Dichloroacetate, stimulated OXPHOS by increasing PDH activity [54]. Another study found that various glioma cell lines had high dependency on mitochondrial OXPHOS for ATP production [55], and that glioma cells with preference for aerobic glycolysis could transition to OXPHOS under glucose deprived conditions [56]. This means that cancer cells can undergo metabolic reprogramming and are equipped with the ability to shift between glycolysis 


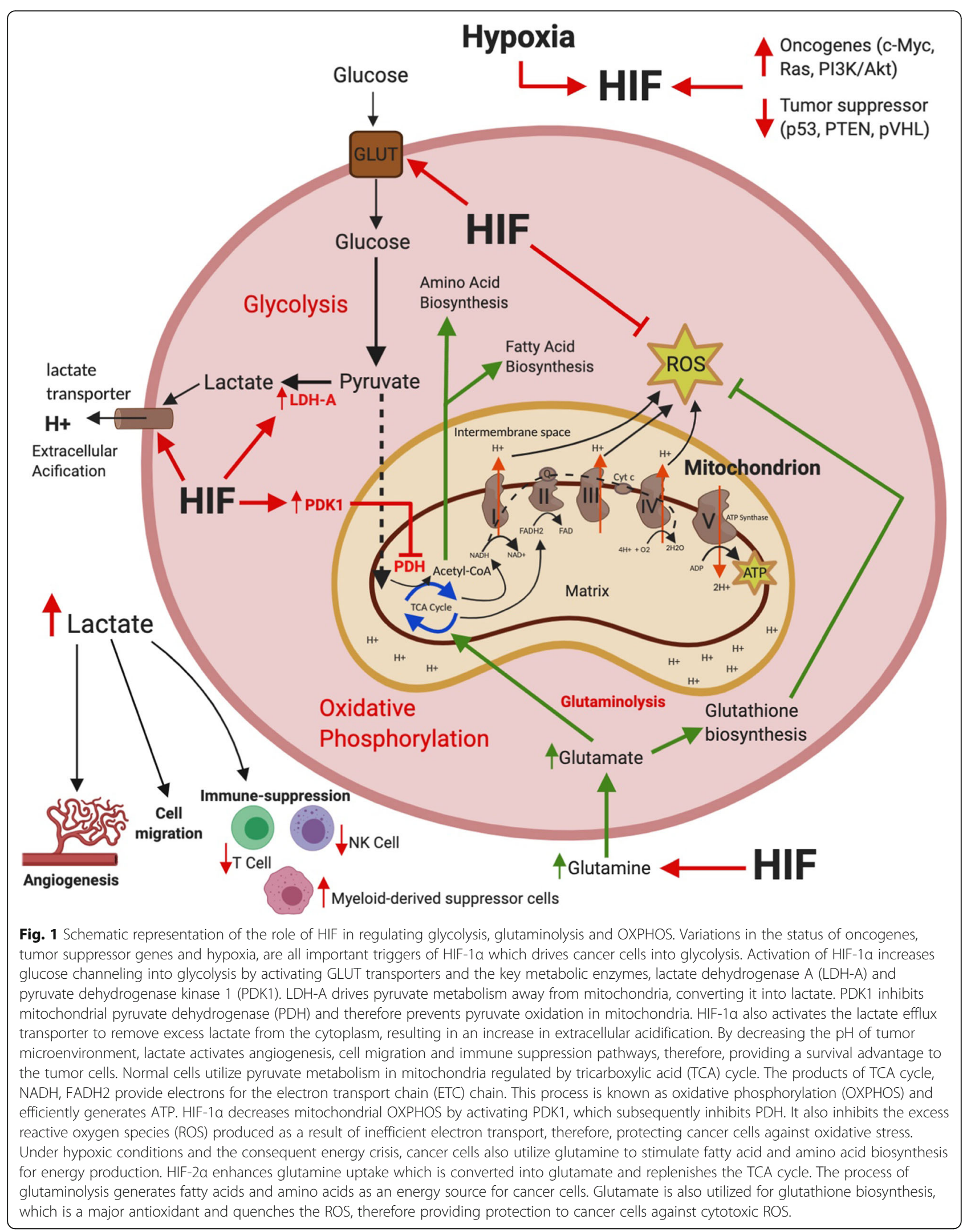


and OXPHOS depending upon the conditions in the tumor microenvironment.

The OXPHOS metabolic pathway involves the mitochondrial uptake of pyruvate being directed to the TCA cycle. This pathway regulates ATP production through the electron transport chain (ETC) complexes I-IV, present in the inner mitochondrial membrane [53]. The electron donors $\mathrm{NADH}, \mathrm{FADH}_{2}$, and succinate, activate the ETC complexes, and the transport of electrons across the ETC complexes leads to the pumping of $\mathrm{H}+$ ions from the mitochondrial matrix to the intermembrane space [53]. Here, oxygen acts as the final electron acceptor and transports protons across the complex IV. This resulting proton gradient stimulates proton flow into the mitochondrial matrix through complex V - ATP synthase which generates ATP production (summarized in Fig. 1).

\section{Cancer Stem Cells and Mitochondrial Metabolism}

CSCs, a subpopulation of cancer cells, contribute to tumor heterogeneity and play a vital role in tumor recurrence and metastatic dissemination [57]. These features of CSCs limit the efficacy of anti-tumor therapies and prevent uniform therapeutic effect across the entire tumor region due to the resistance to chemo- and radiotherapy [57-59]. CSCs undergo dynamic and reversible changes and exhibit a robust behavior due to functions including rapid DNA repair, resistance to oxidative stress, and adaptation to a hypo-nutrient microenvironment [60]. These resistant CSCs are highly dependent on mitochondrial biogenesis for survival and propagation [58, 61]. Vlashi et al. 2011 observed that unlike differentiated glioma cells, GSCs are less glycolytic and predominantly reliant on mitochondrial function and OXPHOS, producing large amounts of ATP [62]. These differences support the idea of inherent metabolic plasticity of cancer cells and the dynamic nature of cancer metabolism, which is highly influenced by factors such as the origin of cancer cells, mutational status, and nutrient availability in the tumor microenvironment [63]. This furthers our understanding of the radioresistance mechanisms of gliomas and suggests that there are two potential populations in HGGs that need to be targeted for complete eradication of the tumor i.e. GSCs and glioma differentiated cells. Of these, the resistant GSCs are more important as they could repopulate the tumor mass even after radiotherapy due to the inherent radioresistance. Since GSCs utilize OXPHOS and are generally spared by therapies targeted towards glycolysis, this suggests that using mitochondrial-targeted therapies may be a successful approach in the treatment of resistant and relapsed cancers by eliminating GSCs [62].

Importantly, subtypes of cancer cells within the heterogeneous tumor population could harbour CSC-like phenotypes due to metabolic symbiosis across neighboring cancer cells, promoting tumor development under unfavorable conditions [57]. The concept of metabolic symbiosis refers to the reuse of lactate produced from the hypoxic/glycolytic cells to fuel the ATP production in oxidative cells, thus lactate serves as an important contributor to OXPHOS [64]. Accumulating evidence suggests that both normal brain tissue and gliomas share metabolic symbiosis due to high expression of the two subtypes of monocarboxylate transporters - MCT4 and MCT1 which mediate the lactate shuttle across tumors [65]. Chemo- or radiotherapy induced redox stress could cause upregulation of HIF- $1 \alpha$ which drives the activity of both MCT4- and MCT1- cancer cells [57]. The hypoxic tumor cells are MCT4-positive and undergo glycolysis. They exhibit a Warburg phenotype, producing excess lactate and secreting it via the MCT4. Lactate acts as substrate for oxygenated tumor cells which are MCT1-positive, displaying a 'Reverse Warburg phenotype' by converting the lactate back into pyruvate and providing fuel for mitochondrial OXPHOS. These MCT1positive cancer cells have high mitochondrial abundance and behave similarly to cancer stem-like cells in the heterogeneous population of tumor $[57,66]$. Since antitumor therapies function by increasing ROS, this allows MCT1-positive CSCs to continue to function via the mitochondrial pathway and maintain the tumor population, thus, preventing complete eradication of the tumor tissue [57]. Targeting MCT1 is reported to inhibit tumor growth and could render tumor cells sensitive to radiotherapy [66]. Since MCT1 is highly expressed in HGGs [67], targeting mitochondria and MCT1 could interrupt the symbiosis and decrease the ability of tumor to utilize the key metabolic substrates [64]. Additionally, inhibition of mitochondrial OXPHOS could increase tumor oxygenation and enhance the radiosensitivity of tumors, thus helping eradicate the robust CSCs population and improving treatment responses in cancers.

The tumor microenvironment plays a significant role in maintaining the stemness of CSCs. CSCs reside in niches with adjacent cells which provide growth factors, cytokines, and other extracellular matrix components, essential for tumor development and conserving the metabolic phenotypes of CSCs that underlie therapeutic resistance and distant metastasis [60]. A hypoxic microenvironment, with elevated expression of both HIF- $1 \alpha$ and HIF- $2 \alpha$, is also reported to be advantageous for the survival and propagation of CSCs [60]. Studies show that GSCs reside amongst endothelial cells, forming a perivascular niche, where high osteopontin expression enables GSCs to acquire stem celllike phenotypes and promotes radioresistance via the interaction of hypoxia-induced HIF- $2 \alpha$ with the stem cell marker CD44 $[68,69]$. This finding further establishes the link between tumor hypoxia and GSCs with radioresistance and suggests that targeting both of these elements is needed to improve radiation responses in gliomas. 


\section{Targeting Tumor Hypoxia by inhibiting Mitochondrial Metabolism}

Since tumor hypoxia is identified as a barrier to successful radiotherapy treatment, targeting hypoxia is an attractive approach to overcome radioresistance and enhance the effectiveness of radiotherapy [70]. In the past, research into alleviating tumor hypoxia was predicated on approaches that increase the oxygen supply to tumor regions, including oxygen delivery via hyperbaric oxygen chambers and using oxygen mimetics such as misonidazole and nimorazole which increase radiosensitivity via fixation of radicalinduced DNA damage [71]. Other attempts involved the usage of hypoxia-activated prodrugs/compounds, including tirapazamine, $\mathrm{N}$-oxides, transition metals, and quinones, that use enzymatic reduction reactions to form cytotoxic effector species which specifically eradicate hypoxic cells in tumors [72]. Despite their ability to decrease tumor hypoxia, these approaches did not yield significant clinical outcomes due to toxicity profiles, poor-perfusion and other limitations, and are therefore not used in clinical practice [71]. In contrast to the previous strategies, current research focuses on reducing oxygen demand by decreasing oxygen consumption rate (OCR) as an alternative approach to abolish tumor hypoxia [71]. Computational analysis also suggests that reducing OCR could be more efficacious in attenuating hypoxia and increasing oxygen concentration compared to previous methods of increasing oxygen delivery [73].

A decrease in OCR could be achievable by inhibiting the mitochondrial OXPHOS [53]. Mitochondria is a potential target for alleviating tumor hypoxia as mitochondrial inhibitors are found to decrease tumor cells' demand for oxygen [74]. This occurs because oxygen is required for OXPHOS as it is the terminal electron acceptor in the mitochondrial ETC complexes (see Fig. 1), therefore, targeting ETC complexes could subsequently decrease the oxygen utilization and inhibit OXPHOS. As a result, there would be more oxygen available surrounding the tumor tissue and oxygen concentration would increase. As reoxygenation of radioresistant tumors would enhance their radiosensitivity and increase tumor cell death [70], targeting mitochondria would help abolish tumor hypoxia and therefore, improve the radiation response in HGGs. Moreover, this approach would also be effective in eradicating the radioresistant GSCs which do not respond to antiglycolytic therapies and could further improve the efficacy of radiotherapy in these deadly malignancies.

\section{Other Roles of HIFs in Cancer Metabolism HIFs and Reactive Oxygen Species}

Reduced oxygen tension also increases the production of ROS, therefore increasing cellular redox stress. Cancer cells counter this state by HIF1-mediated modulation of the subunits of ETC complex IV, also known as the cytochrome c oxidase $(\mathrm{COX})$ present in the mitochondria [40]. Under normoxia, cells function by expression of the COX4-1 regulatory subunit [40]. However, hypoxia induces HIF-1 to upregulate the transcription of COX4-2 regulatory subunit and mitochondrial LON protease, which regulates the cleavage of COX4-1 subunit [44]. This subunit switch prevents inefficient electron transfer reactions and accumulation of toxic ROS, therefore, enabling cancer cells to survive under hypoxic microenvironment [40]. Hypoxia also slows down the ETC, therefore causing mitochondrial dysfunction by increasing the ratio of nicotinamide adenine dinucleotide and its oxidized state (NADH: $\mathrm{NAD}^{+}$) [40]. This is critical for the generation of mitochondrial redox couples - glutathione and thioredoxin, which quench the ROS, therefore, maintaining the stability and viability of cancer cells [40]. Low levels of ROS decrease the radiationinduced DNA damage and confers radioresistance to cancer cells.

\section{HIFs and c-MYC Upregulation}

HIFs can also interact with proto-oncogenes such as cMYC, altering tumor metabolism and driving malignant proliferation [44]. The interaction of HIF-1 and c-MYC directs cancer cells to glycolysis by upregulating the glucose transporter 1 (GLUT1) which increases glucose uptake, and hexokinase 2 (HK2) which catalyzes the first step of glycolysis, and PDK1 which suppresses mitochondrial respiration $[75,76]$. Since hypoxia and HIF-1 promote the glycolytic phenotype, the relationship between HIF-1 and c-MYC shows that c-MYC allows cancer cells to adapt to hypoxic microenvironment [77]. Overexpression of c-MYC also maintains mitochondrial TCA cycle activity by activating HIF- $2 \alpha$ mediated glutamine uptake as an alternative energy source and enhancing glutaminolysis, therefore, directing the available carbon into fatty acid, amino acid and nucleotide synthesis [44, 77]. Glutamine metabolism is repeatedly observed in various cancers as a compensatory pathway when cells are under an energy crisis [42]. Moreover, overexpression of MYC confers survival benefit to cancer cells by increasing the synthesis of biomolecules and energy production during hypoxic stress [44], thus signifying that it could be a potential drug target for anti-cancer therapies.

\section{HIFs and PI3K/Akt/mTOR Pathway}

Besides hypoxia, HIF- $1 \alpha$ is also regulated by the phosphatidylinositol - 4,5 - bisphosphate 3 - Kinase (PI3K)/ protein kinase B (Akt)/mTOR pathway [78]. The PI3K/ Akt pathway is involved in cell signaling, angiogenesis, cell proliferation, migration, and apoptosis [78]. It is upregulated in various cancers owing to several mutations such as loss of PTEN and plays a significant role in tumor development [78]. The mTOR pathway directly controls mitochondrial respiration and oxygen consumption, and 
mTOR inhibition result in a decrease in mitochondrial oxidative function [79]. The mTOR inhibition can also activate its downstream target AMPK, which is a sensor of the energetic status of cells and is known to control proliferation in some cancers $[80,81]$. In addition to mTOR inhibition, inhibitors of PI3K/Akt can decrease HIF- $1 \alpha$ expression, inhibit cell proliferation, and trigger cell death, and therefore are detrimental to tumor progression [78].

\section{Repurposing Drugs for HGG Treatment}

Repurposing drugs for cancer treatment is a cost-effective approach as the knowledge of dosage, safety, and side effects profile is already available. An understanding of the radioresistance mechanisms of HGGs has revealed that both tumor hypoxia and GSCs are significant contributors to tumor recurrence and resistance to chemo- and radiotherapy. Since GSCs are highly dependent on mitochondrial biogenesis [62], using drugs that specifically target hypoxia and mitochondrial metabolism is an attractive strategy to abolish hypoxia and eradicate these resistant GSCs. Inhibition of these pathways would enhance the effectiveness of radiotherapy and could therefore ameliorate the survival outcomes of patients with HGGs.

Various anti-mitochondrial drugs that inhibit OXPHOS either directly or indirectly have been explored as agents for anti-cancer therapy. These include the mitochondrial complex I inhibitors - biguanides (metformin and phenformin), BAY 87-2243, IACS-010759, Fenofibrate, and VLX600; complex II inhibitors - Lonidamine, VLX600, and Alpha-tocopheryl succinate; complex III inhibitors - Atovaquone; complex IV inhibitors - Arsenic trioxide and VLX600; mitochondrial protein synthesis inhibitors - Tigecycline and Doxycycline; and mitochondrial transfer inhibitors - NOX2 inhibitors and CD38 inhibitors [82]. Studies into these anti-mitochondrial drugs found that biguanides such as metformin reduce OCR by $10-20 \%$; however, the anti-parasitic drug, atovaquone, exhibited a more profound effect on OXPHOS inhibition as it reduced the OCR by greater than $80 \%[26,83]$. This leads to the assumption that anti-parasitic drugs with a similar mode of action may be more potent in abolishing tumor hypoxia and increasing radiosensitivity of tumor tissue and shifts the focus to understanding their underlying mechanisms.

Repurposing anti-parasitic drugs that have previously displayed promising results against various cancer types, including glioblastoma, may also yield substantial results against DIPG. Anti-parasitic drugs, such as atovaquone, ivermectin, mefloquine, proguanil, and quinacrine could inhibit tumor growth by targeting various cancer pathways. These drugs have the potential to alleviate tumor hypoxia by decreasing OCR, induce mitochondrial dysfunction and oxidative stress by inhibiting the mitochondrial ETC, and upregulate mechanisms of DNA damage; all of these would lead to an increase in cancer cell death.
An increase in apoptosis of GSCs and reoxygenation of radioresistant HGGs by these drugs could increase the radiosensitivity of HGG tumor tissue and result in improved radiation response (summarized in Fig. 2). Apart from atovaquone, which has shown some promising radiosensitizing effect against hypopharyngeal carcinoma [84], the ability of other anti-parasitic drugs to sensitize tumor cells to radiotherapy have not been explored and this area is worth pursuing (see Table 1). A recent clinical trial identifies atovaquone as a hypoxia modifier in non-small-cell-lung carcinoma, suggesting that if atovaquone demonstrates a reduction in tumour hypoxia, it would pave a pathway to assess it in combination with radiation in further trials (trial number NCT02628080). Importantly, the inherent ability of these anti-parasitic drugs to penetrate the BBB further directs our attention to use them for research in the management of HGGs.

\section{Mechanism of Action of Anti-parasitic Drugs Atovaquone}

Atovaquone, an anti-malarial drug, is FDA-approved for the treatment of lung infection called pneumocystis pneumonia, and for toxoplasmosis [85]. It is efficacious against a variety of protozoa such as plasmodium spp., Toxoplasma gondii., P. carinii., and Babesia spp. [128]. It was particularly developed to treat malarial infections and targeted the mitochondrial function in Plasmodium spp. by inhibiting the mitochondrial complex III, also known as cytochrome bc1 complex [85]. Atovaquone is ubiquinone (also known as coenzyme Q) analogue and blocks its binding site on cytochrome bc1 complex, therefore, inhibiting the transport of electrons into complex III [128]. This leads to a significant decline in mitochondrial membrane potential (MMP), disruption of key enzymes linked to the ETC, suppression of OXPHOS, and consequently results in a complete failure of malarial mitochondrial function [128]. Additionally, the anti-malarial activity of atovaquone is enhanced by synergizing it with proguanil [128].

Atovaquone is observed to decrease the OCR and alleviate hypoxia in various cancer cell lines by targeting mitochondrial complex III [84]. This effect has also been observed in animal models. Decreasing OCR is an attractive strategy to enhance the radiosensitivity of hypoxic tumors, and if reproduced in humans, it would render the tumors more sensitive to radiotherapy, thus improving clinical outcomes [26]. Fiorillo et al. 2016 illustrated that atovaquone reduces cell proliferation and induces apoptotic cell death in breast CSCs by inhibition of mitochondrial complex III and OXPHOS [85]. This resulted in a decrease in mitochondrial respiration, ATP levels, and MMP, along with a subsequent increase in cytotoxic ROS [85]. Moreover, atovaquone was found to decrease OCR and diminish hypoxia in $\mathrm{FaDu}$ (hypopharyngeal carcinoma), HCT116 (colorectal carcinoma) and H1299 (lung carcinoma) cell lines. It also reduced 


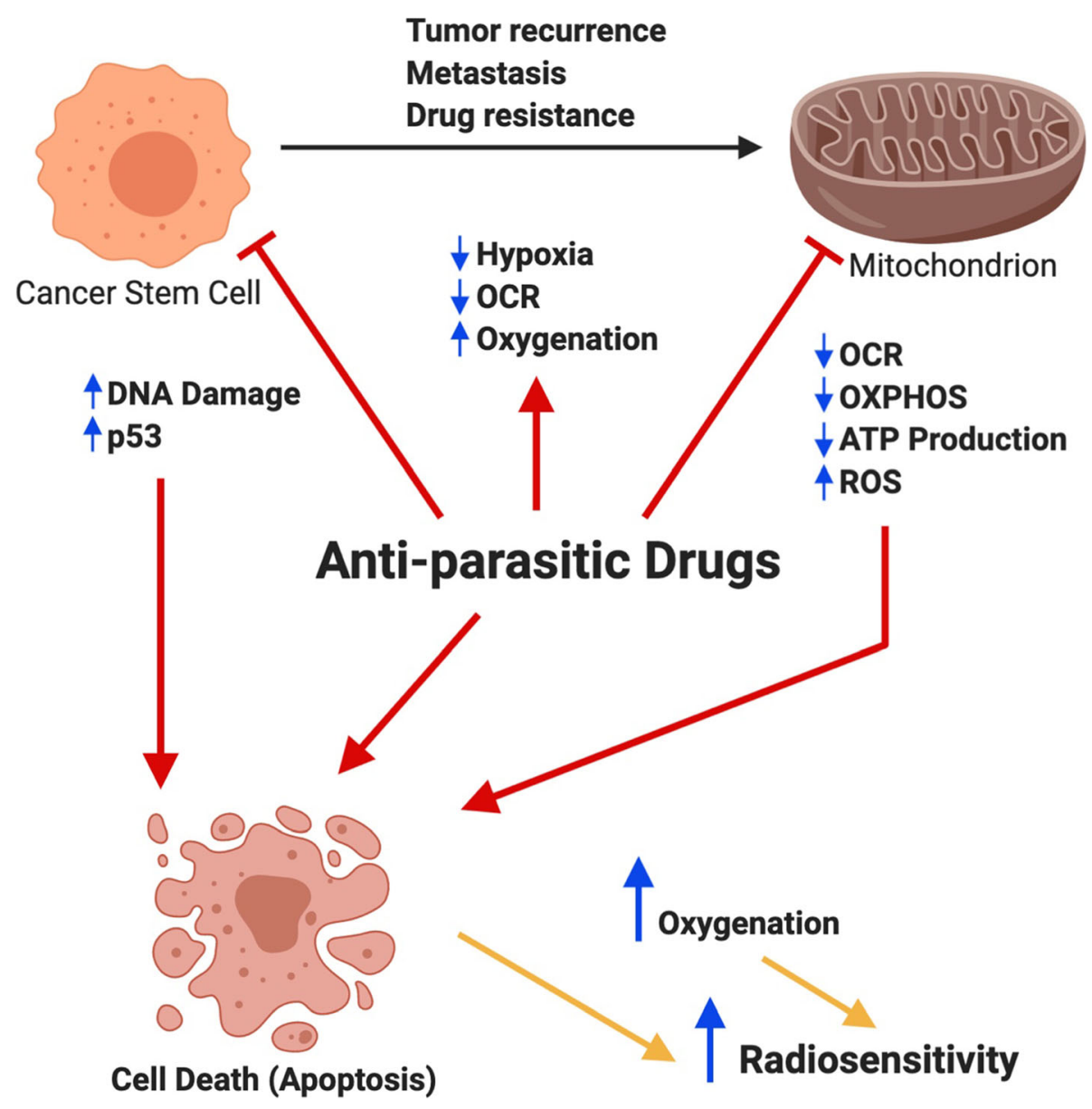

Fig. 2 Targeting tumor hypoxia, mitochondrial function, and activating DNA damage pathways via repurposing anti-parasitic drugs. Cancer stem cells (CSCs) are highly dependent on mitochondrial function for propagation and are vital contributors to tumor recurrence, metastasis and resistance to chemo- and radiotherapy. Here, we propose the use of anti-parasitic drugs such as atovaquone, ivermectin, mefloquine, proguanil, and quinacrine to eradicate glioma stem cells (GSCs) and glioma differentiated cells by targeting various cancer metabolic pathways. These drugs alleviate tumor hypoxia and decrease the oxygen consumption rate (OCR) by targeting mitochondrial electron transport chain (ETC) complexes, subsequently inhibiting OXPHOS and enhancing oxidative stress. By decreasing hypoxia, these drugs could potentially increase oxygenation around the tumor tissue. Moreover, these drugs also upregulate mechanisms of DNA damage and tumor suppressor p53. As a consequence, these drugs are proposed to induce apoptosis of GSCs, which, along with an increase in oxygenation (due to reduction in tumor hypoxia), should enhance the radiosensitivity of tumor cells. Combining the anti-parasitic drugs with radiotherapy is therefore an attractive approach to increase oxygen availability and eradicate therapy resistant GSCs and enhance the efficacy of radiotherapy

hypoxia in FaDu and HCT116 mouse xenografts models and significantly decreased tumor growth in the $\mathrm{FaDu}$ xenograft model in combination with radiation [84]. Other studies on the anti-cancer activity of atovaquone reveal that it induced apoptosis and inhibited cell growth in cervical cancer, thyroid cancer, retinoblastoma, and renal cell carcinoma (RCC), by suppressing mitochondrial respiration [86-89]. It also enhanced the sensitivity of retinoblastoma and RCC to chemotherapy and immunotherapy [88, 89]. Since mitochondrial biogenesis differs amongst cancers, the anti-cancer effect of atovaquone are more likely to eradicate those cancers with a higher dependency on mitochondrial biogenesis [86].

Atovaquone also targets signal transducer and activator of transcription 3 (STAT3), which is actively expressed in many solid and hematological malignancies [129]. Upregulated STAT3 contributes to tumorigenesis by increasing cancer proliferation, metastasis, drug resistance, and prevents apoptosis [129]. Atovaquone is found to inhibit STAT3 in thyroid cancer, acute myeloid leukemia (AML), and glioblastoma, therefore decreasing cell viability and inducing apoptosis in these cancers $[87,90,91]$.

\section{Ivermectin}

Ivermectin is FDA-approved for the management of onchocerciasis, intestinal strongyloidiasis, pediculosis capitis, and inflammatory lesion - rosacea [93]. It belongs to a family of macrocyclic lactone compounds called Avermectins, all of which bind to the glutamate-gated chloride ion channels (Glu-Cl) and interact with gamma- 
Table 1 Summary of the evidence of anti-neoplastic role of the anti-parasitic drugs: their current indications, cellular cytotoxic mechanisms of cancers, BBB penetration profile and radiosensitivity response

\begin{tabular}{|c|c|c|c|c|c|c|c|}
\hline $\begin{array}{l}\text { Drug } \\
\text { Name }\end{array}$ & Indications & Mechanism of Action & $\begin{array}{l}\text { Efficacy in } \\
\text { Cancers }\end{array}$ & $\begin{array}{l}\text { Efficacy in } \\
\text { Brain } \\
\text { Cancers }\end{array}$ & $\begin{array}{l}\text { BBB } \\
\text { Penetrability }\end{array}$ & Radiosensitivity & Source \\
\hline Atovaquone & $\begin{array}{l}\text { FDA-labelled: } \\
\text { - Pneumocystis } \\
\text { Pneumonia } \\
\text { Non-FDA labelled: } \\
\text { - Malaria } \\
\text { - Toxoplasma } \\
\text { Encephalitis } \\
\text { - Toxoplasmosis } \\
\text { - Babesiosis }\end{array}$ & $\begin{array}{l}\text { - Mitochondrial dysfunction } \\
\text { and oxidative stress } \\
\text { - Akt/AMPK/mTOR pathway } \\
\text { Inhibitor } \\
\text { - STAT3 Inhibitor }\end{array}$ & $\begin{array}{l}\text { - Breast Cancer } \\
\text { - Hypopharyngeal } \\
\text { carcinoma } \\
\text { - Colorectal } \\
\text { Carcinoma } \\
\text { - Lung Carcinoma } \\
\text { - Cervical Cancer } \\
\text { - Retinoblastoma } \\
\text { - Renal Cell } \\
\text { Carcinoma } \\
\text { - Acute Myeloid } \\
\text { Leukemia } \\
\text { - Thyroid } \\
\text { Carcinoma }\end{array}$ & - Glioblastoma & Yes & $\begin{array}{l}\text { - Hypopharyngeal } \\
\text { Carcinoma }\end{array}$ & [84-92] \\
\hline Ivermectin & $\begin{array}{l}\text { FDA-labelled: } \\
\text { - Infection by } \\
\text { Onchocerca } \\
\text { volvulus } \\
\text { - Intestinal } \\
\text { strongyloidiasis } \\
\text { - Pediculosis } \\
\text { Capitis } \\
\text { - Rosacea } \\
\text { Non-FDA labelled: } \\
\text { - Ascariasis } \\
\text { - Infection by Loa } \\
\text { loa } \\
\text { - Cutaneous larva } \\
\text { migrans } \\
\text { - Enterobiasis } \\
\text { - Infection by } \\
\text { Wuchereria } \\
\text { bancrofti } \\
\text { - Infestation by } \\
\text { Phthirus pubis } \\
\text { - Mansonelliasis } \\
\text { - Scabies }\end{array}$ & $\begin{array}{l}\text { - Mitochondrial dysfunction } \\
\text { and oxidative stress } \\
\text { - Akt/mTOR pathway inhibitor } \\
\text { - Induces cytostatic autophagy } \\
\text { by targeting PAK1/Akt axis } \\
\text { - Induces chloride dependent } \\
\text { membrane hyperpolarization } \\
\text { - WNT/TCF pathway inhibitor } \\
\text { - Induces DNA fragmentation } \\
\text { and chromatin condensation } \\
\text { - Inhibition of ROS-TFE3- } \\
\text { dependent autophagy and } \\
\text { enhancing apoptosis }\end{array}$ & $\begin{array}{l}\text { - Renal Cell } \\
\text { Carcinoma } \\
\text { - Chronic Myeloid } \\
\text { Leukemia } \\
\text { - Breast Cancer } \\
\text { - Ovarian Cancer } \\
\text { - Colon Cancer } \\
\text { - Leukemia } \\
\text { - Melanoma } \\
\text { - Oesophageal } \\
\text { squamous cell } \\
\text { carcinoma } \\
\text { - Cervical Cancer }\end{array}$ & $\begin{array}{l}\text { - Glioblastoma } \\
\text { - Neuroglioma }\end{array}$ & $\begin{array}{l}\text { Limited (increases } \\
\text { with increase in } \\
\text { concentration) }\end{array}$ & & $\begin{array}{l}{[93-} \\
104]\end{array}$ \\
\hline Mefloquine & $\begin{array}{l}\text { FDA-labelled: } \\
\text { - Malaria }\end{array}$ & $\begin{array}{l}\text { - PI3K/Akt/mTOR inhibitor } \\
\text { - Mitochondrial dysfunction } \\
\text { and oxidative } \\
\text { stress } \\
\text { - Lysosomal disruption } \\
\text { - Disrupts endolysosomal } \\
\text { RAB5/7 } \\
\text { - Targets B-catenin pathway } \\
\text { - Inhibits NF-kB signaling } \\
\text { - Induces autophagy and } \\
\text { endoplasmic reticulum stress }\end{array}$ & $\begin{array}{l}\text { - Prostate Cancer } \\
\text { - Gastric Cancer } \\
\text { - Cervical Cancer } \\
\text { - Acute Myeloid } \\
\text { Leukemia } \\
\text { - Chronic } \\
\text { Lymphocytic } \\
\text { Leukemia } \\
\text { - Colorectal cancer } \\
\text { - Liver cancer } \\
\text { - Breast Cancer }\end{array}$ & - Glioblastoma & Yes & & $\begin{array}{l}{[105-} \\
114]\end{array}$ \\
\hline Proguanil & $\begin{array}{l}\text { FDA-labelled: } \\
\text { - Malaria, } \\
\text { Plasmodium } \\
\text { Falciparum } \\
\text { Non-FDA labelled: } \\
\text { - Malaria, } \\
\text { Plasmodium } \\
\text { Vivax }\end{array}$ & $\begin{array}{l}\text { - Mitochondrial dysfunction } \\
\text { and oxidative stress }\end{array}$ & $\begin{array}{l}\text { - Colon Cancer } \\
\text { - Bladder Cancer }\end{array}$ & & Yes & & [115] \\
\hline Quinacrine & $\begin{array}{l}\text { Non-FDA labelled: } \\
\text { - Malaria } \\
\text { - Giardiasis } \\
\text { - Tapeworm } \\
\text { infection } \\
\text { - Systemic Lupus }\end{array}$ & $\begin{array}{l}\text { - DNA intercalator, inhibits } \\
\text { DNA repair pathways } \\
\text { - FACT c-trapping } \\
\text { - Induces apoptosis via } \\
\text { TRAIL signaling, modulating } \\
\text { topoisomerases, inhibiting }\end{array}$ & $\begin{array}{l}\text { - Breast Cancer } \\
\text { - Colon Carcinoma } \\
\text { - Ovarian Cancer } \\
\text { - Non-small cell } \\
\text { lung cancer } \\
\text { - Diffuse large B- }\end{array}$ & • Glioblastoma & Yes & & $\begin{array}{l}{[116-} \\
127]\end{array}$ \\
\hline
\end{tabular}


Table 1 Summary of the evidence of anti-neoplastic role of the anti-parasitic drugs: their current indications, cellular cytotoxic mechanisms of cancers, BBB penetration profile and radiosensitivity response (Continued)

\begin{tabular}{|c|c|c|c|c|c|c|c|}
\hline $\begin{array}{l}\text { Drug } \\
\text { Name }\end{array}$ & Indications & Mechanism of Action & $\begin{array}{l}\text { Efficacy in } \\
\text { Cancers }\end{array}$ & $\begin{array}{l}\text { Efficacy in } \\
\text { Brain } \\
\text { Cancers }\end{array}$ & $\begin{array}{l}\text { BBB } \\
\text { Penetrability }\end{array}$ & Radiosensitivity & Source \\
\hline & $\begin{array}{l}\text { erythematosus } \\
\text { - Rheumatoid } \\
\text { arthritis } \\
\text { - Malignant } \\
\text { pleural effusions } \\
\text { - Prevention of } \\
\text { recurrent } \\
\text { pneumothorax } \\
\text { - Female } \\
\text { sterilization }\end{array}$ & $\begin{array}{l}\text { NF-kB and inducing p53 } \\
\text { - Arachidonic acid pathway } \\
\text { inhibitor } \\
\text { - Induces cytostatic autophagy } \\
\text { and inhibits cytoprotective } \\
\text { autophagy } \\
\text { - Modulates cell cycle arrest }\end{array}$ & $\begin{array}{l}\text { cell lymphoma } \\
\text { - Colorectal } \\
\text { Cancer } \\
\text { - Leukemia } \\
\text { - Renal Cell } \\
\text { Carcinoma } \\
\text { - Melanoma } \\
\text { - Gastric Cancer } \\
\text { - Anaplastic } \\
\text { Thyroid Cancer }\end{array}$ & & & & \\
\hline
\end{tabular}

aminobutyric acid (GABA) gated $\mathrm{Cl}^{-}$channels in the nerve and muscle cells of the parasites [130]. This results in an increased build-up of $\mathrm{Cl}^{-}$ions, causing hyperpolarization of parasitic cell membranes, and leads to muscle paralysis and cell death [131]. The safety profile of ivermectin in mammals is confirmed by the presence of the intact $\mathrm{BBB}$ which secures GABA-sensitive neurons, therefore protecting against toxic effects of avermectins [131]. Ivermectin exhibits limited BBB penetrability due to the plasma membrane efflux pump p-glycoprotein which limits the drug intake into the brain [132]. However, a study found that avermectins, including ivermectin has the potential to inhibit p-glycoprotein efflux transporter and could penetrate the BBB at the appropriate concentrations [94, 133, 134]. This provides support for further research into the dosages required for $\mathrm{BBB}$ penetrability of ivermectin.

Interestingly, ivermectin has shown promising anticancer efficacy in various cancers by increasing mitochondrial dysfunction, inducing oxidative stress, and energy crisis [130]. By selectively targeting the ETC complex I, it inhibits the electron transport to the subsequent ETC complexes and causes a decline in MMP [130]. This results in a decrease in OCR, leading to suppression of mitochondrial respiration and ATP production, and also production of cytotoxic ROS which potentiate DNA damage [130]. A study by Zhu et al. 2017 observed that by targeting mitochondrial function, ivermectin causes apoptosis and suppresses cellular proliferation in a variety of RCC cell lines and also significantly impairs tumor growth in RCC xenograft mouse model [95]. Also, ivermectin-induced oxidative stress and mitochondrial dysfunction upregulated caspasedependent apoptosis in chronic myeloid leukemia (CML) cells and inhibited tumor size in CML xenograft models [96]. It also sensitized the CML cells to BCR-ABL tyrosine kinase inhibitors, particularly, nilotinib and dasatinib [96]. Moreover, it exhibited preferential toxicity to both RCC and CML cells and spared the healthy cells due to the high reliance of these cancers on mitochondrial biogenesis $[95,96]$. The inhibitory effects of ivermectin were also visualized in both in vitro and in vivo subcutaneous glioblastoma models, where it inhibited proliferation, induced caspase-dependent apoptosis, and potentiated angiogenic inhibition [97]. These responses were mediated via the role of ivermectin in depolarizing the MMP with an increase in ROS production, and inhibition of the capillary network formation [97].

Furthermore, ivermectin was also found to induce oxidative stress in glioblastoma cells by inhibiting the Akt/ mTOR pathway [97]. The mTOR pathway is critical to mitochondrial function and acts as a cellular switch between glycolysis and mitochondrial respiration, such that mTOR inhibitors tend to decrease OCR and mitochondrial respiration directly and shift the cells towards a glycolytic phenotype [79]. The cytotoxic profile of ivermectin was not observed in mitochondrial-deficient cells or cells exposed to antioxidants, thus validating the role of ivermectin in inhibition of mitochondrial function [97]. Moreover, it induced caspase-mediated apoptosis and inhibited cell cycle progression in neuroglioma cells and suppressed tumor growth in in vivo xenografts [94].

Studies have also demonstrated that ivermectin induces cytostatic autophagy in breast cancer, and inhibits proliferation of ovarian cancer and oesophageal squamous cell carcinoma, by inhibition of PAK1 protein [98-100]. Moreover, it induces apoptosis in various other cancer such as melanoma by inhibition of ROS-TFE3 dependent autophagy; in leukemia by increasing chloride ions influx and ROS production; and in colon cancer cells via blocking the WNT/TCF pathway [101-103]. It also decreased cell viability of cervical cancer cells by mechanisms including mitochondrial dysfunction, increased ROS generation, DNA fragmentation, and chromatin condensation, and arresting cells in G1/S phase [104].

\section{Mefloquine}

Mefloquine, a quinolinemethanol, is FDA-approved for the treatment of malarial infection caused by chloroquine-resistant Plasmodium falciparum and is an 
effective blood schizonticide for P. vivax [135]. It has been clinically available for thirty years and known to concentrate in the lysosomes of P. falciparum; however, the exact mechanism of action remains unknown. Recent investigation has found that mefloquine inhibits protein synthesis by interacting with the GTPaseassociated center of the $80 \mathrm{~S}$ ribosomal subunit in $P$. falciparum and therefore kills the malarial parasite [136].

Mefloquine has demonstrated anti-cancer efficacy across various cancer cell lines and has been repurposed in the therapeutic targeting of several cancer signaling pathways. Yan et al. 2013 observed that mefloquine reduced the cell viability of prostate cancer cells by altering MMP and producing excess cytotoxic ROS, which decreased the phosphorylation of Akt and triggered JNK, ERK and AMPK signaling pathways [105]. Interestingly, mefloquine did not inhibit the proliferation of normal human fibroblasts, thus indicating that it selectively targets the cancer cells [105]. Another study reported that mefloquine prevents the proliferation of the gastric cancer cells and reduced tumor growth in xenograft mouse models by inhibition of PI3K/Akt/mTOR pathway [106]. Similarly, it also displayed cytotoxicity against cervical cancer cells by targeting mitochondrial function and deactivating the mTOR pathway [107]. An increase in levels of PARP cleavage protein, which inhibits PI3K/ Akt system, was also observed [107]. The PI3K/Akt pathway is critical for protecting MMP as it inactivates pro-apoptotic BAD protein and reduces cellular oxidative stress [137]. Activation of the Akt system also phosphorylates various downstream regulatory proteins such as BAD, caspase-9, FKHR, and GSK3 $\beta$, which protects against cellular stress [137]. Similarly, the mTOR pathway is highly sensitive to mitochondrial dysfunction, and inhibition of this pathway results in a decrease in OCR, mitochondrial respiration, and overall mitochondrial activity [79]. Hence, targeting the PI3K/Akt/mTOR pathway in cancer cells would directly influence the mitochondrial function and trigger cell death.

Mefloquine also stimulated apoptotic cell death in breast cancer by inhibiting autophagy and decreased the proliferative and self-renewal capacity of liver CSCs by targeting the $\beta$-catenin pathway $[108,109]$. It inhibited tumor proliferation and decreased tumor growth in colorectal cancer xenograft mouse models by targeting NF- $\mathrm{kB}$ and the downstream signaling pathways [110]. It further prevented autophagic degradation of defective mitochondria in colorectal CSCs by suppression of RAB5/7, LAMP1/2, and PINK1/PARKIN, therefore resulting in increased mitochondrial dysfunction and cellular apoptosis [111].

Furthermore, mefloquine was also found effective in inducing cell death in AML, chronic lymphocytic leukemia (CLL), and glioblastoma through disruption of lysosomes [112-114]. Lysosomal disruption releases the catalytic proteases cathepsins into the cytosol, which activates mechanisms of apoptosis [113]. Mefloquine stimulates the release of cathepsins from lysosomes in AML and initiates mitochondria-mediated cell death [113]. In glioblastoma, mefloquine disturbed the lysosomal stability and increased the levels of caspase-3, inducing cell death regardless of the p53 status [114]. It was also found to be more potent than chloroquine at inducing glioblastoma cell death and exhibited a better BBB penetrability profile [114].

\section{Proguanil}

The biguanide proguanil was first developed as an antimalarial drug for the management of acute $P$. vivax malaria; it was initially used alone and later administered in combination with chloroquine or atovaquone and the combination was found to be highly effective [138]. It is metabolized into cycloguanil, which regulates inhibition of parasite dihydrofolate reductase [138]. Another synergistic combination of proguanil and atovaquone is effective against $P$. falciparum malaria; both of these drugs target the parasite $P$. falciparum's pre-erythrocytic and erythrocytic stages and induces causal and suppressive prophylaxis [139].

Proguanil enhances the activity of atovaquone in collapsing MMP and causing mitochondrial dysfunction [139]. Despite of being a complex I inhibitor; proguanil does not inhibit cellular and mitochondrial respiration as its penetrability into the mitochondria is limited [140]. However, proguanil still displayed the highest growth inhibition of colon and bladder cancer cell compared to other biguanides [115]. This points to the intriguing possibility of the extramitochondrial cytotoxic activity of proguanil and also suggests its potential role as an anti-cancer agent [115].

\section{Quinacrine}

Quinacrine, an acridine derivative, was initially used for the prophylaxis and management of the malarial infection [141]. It is clinically available as quinacrine dihydrochloride and is effective against the treatment of various conditions, including malaria, giardiasis [142], and tapeworm infection [143]. Quinacrine's effectiveness has also been reported in autoimmune inflammatory conditions, including systemic lupus erythematosus [144], and rheumatoid arthritis [145]. Moreover, it is efficacious in the treatment of pleural effusions in cancer patients [146] and also prevents spontaneous pneumothorax in patients with increased recurrence risk [147]. Quinacrine has also been utilized for safer female sterilization as it causes fibrosis and occlusion of fallopian tubes [148], and is currently under investigation for managing Creutzfeldt-Jacob disease [149].

The anti-cancer potential of quinacrine has been extensively explored, revealing various therapeutic targets. Due 
to its low toxicity profile, minimal side effects, and interference with many cancer signaling pathways, quinacrine offers compelling evidence as a promising antineoplastic agent [116]. The cytotoxic mechanisms of quinacrine include its ability to intercalate into DNA and insert between adjacent base pairs resulting in DNA damage [150]. It also prevents DNA damage repair by interfering with the nuclear proteins and inhibits both DNA and RNA polymerases, topoisomerases, telomerase, and upregulates tumor necrosis factor-related apoptosis-inducing ligand (TRAIL) therefore promoting apoptosis [116]. Quinacrine stimulates TRAIL binding with death receptors 4 and 5 (DR4 and DR5) and upregulates mitochondrial intrinsic apoptotic cascade [116]. It abrogates the arachidonic acid pathway by directly targeting the enzyme phospholipase A2 (PLA2), resulting in a decline in production of prostanoids (COX), leukotrienes (LOX), and eicosanoids (MOX/CYP450), as these prevent cell death and sustain cancer cell survival [150]. Moreover, quinacrine intercalates into DNA and alters the chromatin structure by inducing FACT (facilitates chromatin transcription) complex chromatin trapping; this leads to suppression of the NF- $\mathrm{kB}$ pathway and phosphorylation of the tumor suppressor protein p53 [116]. Hence, quinacrine has the potential to be effective against various cancers by targeting single or multiple signaling pathways and inducing apoptosis. The DNA damaging potential of quinacrine makes it an effective candidate to be combined with radiotherapy and could significantly enhance the efficacy of radiotherapy in HGGs.

A study by Preet et al. 2012 demonstrated that quinacrine targets breast cancer cells and induces cell death, cell cycle arrest, and decreases cell migration through inhibition of topoisomerases and increased DNA damage [117]. It stimulates apoptotic pathways in colon cancer cells by increasing the activity of p53 and p21 and the associated pathways [118]. Research has also found that quinacrine induces autophagic and apoptotic cell death and suppressed tumor growth in ovarian cancer by downregulating p62/SQSTM1 [119]. Furthermore, quinacrine was found to be effective in enhancing apoptosis in diffuse large B-cell lymphoma by downregulating MSI2 NUMB signaling pathway, suppressing c-Myc and arresting cells in S phase [120]. It exhibited a significant tumoricidal effect against RCC by inhibiting NF- $\mathrm{kB}$ and activating p53; reduced cell viability and decreased tumor volume in melanoma xenograft mouse models; induced apoptosis in leukemia cells by depolarization of mitochondria, oxidative stress and downregulation of $\mathrm{Bcl}-2$ and Bcl-2L; and inhibited cell growth and cell cycle progression in gastric cancer cells via activating p53 and caspase-3 dependent apoptotic pathways [121-124].

Quinacrine has also been found to act synergistically with chemotherapy drugs such as carmustine, oxaliplatin, and carboplatin, or inhibitors including cisplatin, 5- fluorouracil, paclitaxel, and sorafenib, across various cancer types [119, 125, 151-155]. It is useful in overcoming resistance against tyrosine kinase inhibitor erlotinib in non-small cell lung cancer via inhibition of NF$\kappa \mathrm{B}, \mathrm{FACT}$, and induction of cell cycle arrest [126]. Moreover, quinacrine inhibited autophagy and reduced the cell viability of human glioblastoma cells both alone and in combination with the kinase inhibitor SI113 by upregulating p62 [127]. Another study by Wang et al. 2017 discovered that quinacrine induced apoptosis in GSCs and enhanced the efficacy of curcumin in eradicating glioma cells both in vitro and in vivo animal models [156]. Due to its ability to penetrate the BBB, induce DNA-damage and apoptosis in cancers, and its efficacy in gliomas, quinacrine seems a promising therapeutic agent for treatment of glioblastoma and DIPG. The DNA damaging role of quinacrine indicates that combining it with radiotherapy could be an effective approach in prolonging patient survival.

Quinacrine was later replaced by chloroquine for the treatment of malaria, however, it continued to be used in the treatment of diseases. Chloroquine, as an antimalarial agent, has also shown promising anti-cancer potential. It is found to disrupt autophagy by blocking the formation of autolysosomes and activating the GRP78/ BiP chaperone which enhances endoplasmic reticulum (ER) stress [157, 158]. Impairment of autophagy results in apoptosis and this could therefore sensitize cancer cells to chemo- and radiotherapy [157]. Interestingly, chloroquine has been shown to act synergistically with TMZ by inducing ER stress [158].

\section{Conclusion and Future Directions}

Glioblastoma and DIPG are deadly and malignant forms of HGGs, contributing to the medical health burden. Despite decades of research and investigating novel agents in clinical trials, both tumors result in high mortality rates and no cure has been established. Patients undergoing radiotherapy experience high rates of recurrence due to the intrinsic radioresistance of the glioma cells. Therapies targeting radioresistance mechanisms are urgently needed to improve radiation response of HGGs as these could increase the overall survival of patients. Tumor hypoxia and alterations in the metabolic status enable cancer cells to achieve the malignant and resistant phenotype. Targeting hypoxia and increasing oxygenation around the tumor tissue is essential for the effectiveness of radiotherapy in HGGs. Inhibiting mitochondrial metabolism could help abolish tumor hypoxia by decreasing the OCR of tumor cells and could subsequently increase the oxygen availability. Therapies targeted towards mitochondria would also be beneficial against GSCs which preferentially rely on mitochondrial metabolism and are key players in tumor recurrence and 
resistance to therapies [62]. Therefore, developing strategies that specifically target tumor hypoxia and inhibit mitochondrial function, or combination strategies to target both glycolysis and OXPHOS, may be beneficial increasing oxygenation and inducing apoptosis of both GSCs and differentiated glioma cells and could improve the efficacy of conventional and biological therapies [54].

There is considerable evidence supporting the antineoplastic role of anti-parasitic drugs (summarized in Table 1). Increasing evidence of the role of anti-parasitic drugs in inducing mitochondrial dysfunction and activating DNA damage pathways, makes them attractive candidates for increasing the radiosensitivity of HGGs. Since these drugs have yielded efficacious results against glioblastoma either alone or in combination with other compounds, this points to the intriguing possibility of their effective role in both glioblastoma and DIPG. Further research should consider investigating these drugs for the treatment of HGGs in combination with radiotherapy. The rationale behind increasing radiosensitivity of glioma cells is via reoxygenation of hypoxic tumor tissue and inducing apoptosis of GSCs, therefore, improving efficacy of radiotherapy (Fig. 2).

A significant limitation in the current literature is that these anti-parasitic drugs have only been investigated in in vitro cancer cell lines and patient-derived xenograft (PDX) implanted in immunocompromised mice. It is important to consider that the successful development of anticancer therapies must consider the interaction between the tumor cells and immune cells. Since the immune system poses a major challenge to the long-term success of the anti-cancer therapies, one possible avenue could be to investigate the antineoplastic role of these drugs in 'humanized' mouse models that closely mimic the patient tumor microenvironment [159]. Therefore, future research should also consider exploring this area for both glioblastoma and DIPG therapy.

In summary, the combination of anti-parasitic drugs and radiotherapy might serve as novel approach towards the management of malignant HGGs and may improve patient survival outcomes. There is need to study the effects of these compounds on interactions between cancer cells and immune system as this could provide further insight into the translation of this approach to clinical practice.

\footnotetext{
Abbreviations

HGG: High-grade glioma; CNS: Central nervous system; DIPG: Diffuse intrinsic pontine glioma; TMZ: Temozolomide; BBB: Blood brain barrier; GSC: Glioma stem cell; CSC: Cancer stem cell; ROS: Reactive oxygen species; PET: Positron emission tomography; TCA: Tricarboxylic acid cycle; HIF: Hypoxia-inducible factor; PHD: Prolyl hydroxylase; OXPHOS: Oxidative phosphorylation; LDHA: Lactate dehydrogenase A; PDK1: Pyruvate dehydrogenase kinase 1; PDH: Pyruvate dehydrogenase; MCT: Monocarboxylate transporter; ETC: Electron transport chain; OCR: Oxygen consumption rate; COX: Cytochrome c oxidase; MMP: Mitochondrial membrane potential; RCC: Renal cell carcinoma; STAT3: Signal transducer and activator of
}

transcription 3; CML: Chronic myeloid leukemia; AML: Acute myeloid leukemia; CLL: Chronic lymphocytic leukemia

\section{Acknowledgements}

The authors acknowledge funding support from NHMRC, Cure Brain Cancer Foundation, The DIPG Collaborative, The Cure Starts Now, The Mark Hughes Foundation, NSW Health, Sydney West Radiation Oncology Network.

\section{Authors' contributions \\ The manuscript was conceived by FM, HS, and EH. The manuscript, table and figures were prepared by FM. Further edits and revision were made by FM, $\mathrm{HS}, \mathrm{GON}$, and EH. All authors read and approved the final manuscript. \\ Figures were created using Biorender.com.}

Availability of data and materials

Not applicable.

Ethics approval and consent to participate

Not applicable.

Consent for publication

Not applicable.

\section{Competing interests}

The authors have declared that no conflict of interest exists.

\section{Author details}

${ }^{1}$ Translational Radiation Biology and Oncology Laboratory, Centre for Cancer Research, Westmead Institute for Medical Research, NSW, Westmead, Australia. ${ }^{2}$ Sydney Medical School, University of Sydney, NSW, Sydney, Australia. ${ }^{3}$ Children's Cancer Research Unit, The Children's Hospital at Westmead, NSW, Westmead, Australia. ${ }^{4}$ Children's Hospital at Westmead Clinical School, Faculty of Medicine and Health, University of Sydney, NSW, Sydney, Australia. ${ }^{5}$ School of Medical Sciences, Faculty of Medicine and Health, University of Sydney, NSW, Sydney, Australia. ${ }^{6}$ Department of Radiation Oncology, Crown Princess Mary Cancer Centre, Westmead Hospital, NSW, Westmead, Australia. ${ }^{7}$ Blacktown Hematology and Cancer Centre, Blacktown Hospital, NSW, Blacktown, Australia.

Received: 27 July 2020 Accepted: 30 September 2020

Published online: 07 October 2020

\section{References}

1. Wen PY, Kesari S. Malignant Gliomas in Adults. N Engl J Med. 2008;359(5): 492-507.

2. Ostrom QT, Cioffi G, Gittleman H, Patil N, Waite K, Kruchko C, et al. CBTRUS Statistical Report: Primary Brain and Other Central Nervous System Tumors Diagnosed in the United States in 2012-2016. Neurooncology. 2019; 21(Supplement 5):v1-100.

3. lacob G, Dinca EB. Current data and strategy in glioblastoma multiforme. J Med Life. 2009;2(4):386-93.

4. Salah Uddin A, Jarmi T. Neurologic manifestations of glioblastoma multiforme clinical presentation 2015 [cited 202018 May]. Available from: https://emedicine.medscape.com/article/1156220-overview.

5. Nakada M, Kita D, Watanabe T, Hayashi Y, Teng L, Pyko I, et al. Aberrant Signaling Pathways in Glioma. Cancers. 2011;3(3):3242-78.

6. Reardon DA, Wen PY. Therapeutic Advances in the Treatment of Glioblastoma: Rationale and Potential Role of Targeted Agents. Oncologist. 2006;11(2):152-64

7. Wick W, Osswald M, Wick A, Winkler F. Treatment of glioblastoma in adults. Ther Adv Neurol Disord. 2018;11:1756286418790452.

8. Hanif F, Muzaffar K, Perveen K, Malhi SM, Simjee SU. Glioblastoma Multiforme: A Review of its Epidemiology and Pathogenesis through Clinical Presentation and Treatment. Asian Pac J Cancer Prev. 2017;18(1):3-9.

9. Stupp R, Mason WP, van Den Bent MJ, Weller M, Fisher B, Taphoorn MJB, et al. Radiotherapy plus concomitant and adjuvant temozolomide for glioblastoma. N Engl J Med. 2005;352(10):987.

10. Hau E, Shen H, Clark C, Graham PH, Koh ES, Mcdonald L. K. The evolving roles and controversies of radiotherapy in the treatment of glioblastoma. $J$ Med Radiat Sci. 2016;63(2):114-23. 
11. Panditharatna E, Yaeger K, Kilburn LB, Packer RJ, Nazarian J. Clinicopathology of diffuse intrinsic pontine glioma and its redefined genomic and epigenomic landscape. Cancer Genet. 2015;208(7-8):367-73.

12. Robison N, Kieran M. Diffuse intrinsic pontine glioma: a reassessment. J Neuro-Oncol. 2014;119(1):7-15.

13. Catherine SG, Yujie T, Nathalene T, Noah EB, Lining L, Marie-Anne D, et al. Functionally defined therapeutic targets in diffuse intrinsic pontine glioma. Nat Med. 2015;21:6.

14. Katherine E. Diffuse intrinsic pontine glioma: Poised for progress. Front Oncol. 2012;2

15. Vanan M, Eisenstat DD. DIPG in children - what can we learn from the past? Front Oncol. 2015;5.

16. Hennika T, Becher OJ. Diffuse Intrinsic Pontine Glioma: Time for Cautious Optimism. J Child Neurol. 2016;31(12):1377-85

17. Kebudi R, Cakir F. Management of Diffuse Pontine Gliomas in Children: Recent Developments. Paediatr Drugs. 2013;15(5):351-62.

18. Narayana A, Kunnakkat S, Chacko-Mathew J, Gardner S, Karajannis M, Raza S, et al. Bevacizumab in recurrent high-grade pediatric gliomas. NeuroOncology. 2010;12(9):985-90.

19. Veringa SJE, Biesmans D, van Vuurden DG, Jansen MHA, Wedekind LE, Horsman I, et al. In Vitro Drug Response and Efflux Transporters Associated with Drug Resistance in Pediatric High Grade Glioma and Diffuse Intrinsic Pontine Glioma. PLoS ONE. 2013;8(4):e61512.

20. Tang L, Wei F, Wu Y, He Y, Shi L, Xiong F, et al. Role of metabolism in cancer cell radioresistance and radiosensitization methods. J Exp Clin Canc Res. 2018;37:1

21. Wang $H$, Jiang $H$, Van De Gucht M, De Ridder M. Hypoxic Radioresistance: Can ROS Be the Key to Overcome It? Cancers. 2019;11:1.

22. Brahimi-Horn M, Chiche J, Pouysségur J. Hypoxia and cancer. J Mol Med. 2007;85(12):1301-7.

23. Baumann R, Depping R, Delaperriere M, Dunst J. Targeting hypoxia to overcome radiation resistance in head \& neck cancers: real challenge or clinical fairytale? Expert Rev Anticancer Ther. 2016;16:751-8.

24. William RW, Michael PH. Targeting hypoxia in cancer therapy. Nat Rev Cancer. 2011;11(6):393

25. Gray LH, Conger AD, Ebert M, Hornsey S, Scott OC. The concentration of oxygen dissolved in tissues at the time of irradiation as a factor in radiotherapy. Br J Radiol. 1953:26(312):638-48.

26. Tharmalingham $\mathrm{H}$, Hoskin $\mathrm{P}$. Clinical trials targeting hypoxia. $\mathrm{Br} J$ Radiol. 2018:92(1093):20170966.

27. G?rard M, Corroyer-Dulmont AL, Lesueur P, Collet SN, Ch?rel M, Bourgeois $M$, et al. Hypoxia Imaging and Adaptive Radiotherapy: A State-of-the-Art Approach in the Management of Glioma. Front Med. 2019;6.

28. Huang Z, Cheng L, Guryanova OA, Wu Q, Bao S. Cancer stem cells in glioblastoma-molecular signaling and therapeutic targeting. Protein Cell. 2010;1(7):638-55.

29. Collingridge DR, Piepmeier JM, Rockwell S, Knisely JPS. Polarographic measurements of oxygen tension in human glioma and surrounding peritumoural brain tissue. Radiother Oncol. 1999;53(2):127-31.

30. Rampling R, Cruickshank G, Lewis AD, Fitzsimmons SA, Workman P. Direct measurement of $\mathrm{pO} 2$ distribution and bioreductive enzymes in human malignant brain tumors. Int J Radiat Oncol Biol Phys. 1994;29(3):427-31.

31. Heddleston JM, Li Z, McLendon RE, Hjelmeland AB, Rich JN. The hypoxic microenvironment maintains glioblastoma stem cells and promotes reprogramming towards a cancer stem cell phenotype. Cell Cycle. 2009; 8(20):3274-84

32. Li Z, Bao S, Wu Q, Wang H, Eyler C, Sathornsumetee S, et al. HypoxiaInducible Factors Regulate Tumorigenic Capacity of Glioma Stem Cells. Cancer Cell. 2009;15(6):501-13.

33. Marampon F, Gravina GL, Zani BM, Popov VM, Fratticci A, Cerasani M, et al Hypoxia sustains glioblastoma radioresistance through ERKs/DNA-PKcs/HIF1[alpha] functional interplay. Int J Oncol. 2014;44(6):2121.

34. Kessler J, Hahnel A, Wichmann H, Rot S, Kappler M, Bache M, et al. HIF-1 alpha inhibition by siRNA or chetomin in human malignant glioma cells: effects on hypoxic radioresistance and monitoring via CA9 expression. BMC Cancer. 2010;10:1.

35. Spence AM, Muzi M, Swanson KR, O'Sullivan F, Rockhill JK, Rajendran JG, et al. Regional hypoxia in glioblastoma multiforme quantified with 18Ffluoromisonidazole positron emission tomography before radiotherapy: correlation with time to progression and survival. Clin Cancer Res. 2008; 14(9):2623.
36. Hustinx R, Eck SL, Alavi A. Potential applications of PET imaging in developing novel cancer therapies. J Nucl Med. 1999:40(6):995.

37. Blandin A-F, Durand A, Litzler M, Guerin E, Jacques Namer I, Guenot D, et al HGG-12. Hypoxia seems to be frequently upregulated in the pediatric high grade glioma and DIPG. Neuro-Oncology. 2017;19(suppl_4):iv25-iv.

38. Yeom K, Lober R, Nelson M, Panigrahy A, Blüml S. Citrate concentrations increase with hypoperfusion in pediatric diffuse intrinsic pontine glioma. J Neuro-Oncol. 2015;122(2):383-9.

39. Rafałowska U. Transport of malate and citrate into rat brain mitochondria under hypoxia and anesthesia. Neurochem Res. 1979;4(3):355-64.

40. Eales K, Hollinshead K, Tennant D. Hypoxia and metabolic adaptation of cancer cells. Oncogenesis. 2016;5(1):e190-e.

41. Gong L, Zhang W, Zhou JD, Lu J, Xiong H, Shi XL, et al. Prognostic Value of HIFs Expression in Head and Neck Cancer: A Systematic Review. PLoS ONE. 2013;8:9.

42. Zheng J. Energy metabolism of cancer: Glycolysis versus oxidative phosphorylation. Oncology letters. 2012;4(6):1151-7.

43. Marchiq I, Pouyssegur J. Hypoxia, cancer metabolism and the therapeutic benefit of targeting lactate/H(+) symporters. J Mol Med. 2016;94(2):155-71.

44. Mucaj V, Shay JE, Simon MC. Effects of hypoxia and HIFs on cancer metabolism. Int J Hematol. 2012;95(5):464-70.

45. Zhou Y, Zhou Y, Shingu T, Feng L, Chen Z, Ogasawara M, et al. Metabolic alterations in highly tumorigenic glioblastoma cells: preference for hypoxia and high dependency on glycolysis. J Biol Chem. 2011;286(37):32843-53.

46. Sonveaux P, Copetti T, De Saedeleer CJ, Végran F, Verrax J, Kennedy KM, et al. Targeting the lactate transporter MCT1 in endothelial cells inhibits lactateinduced HIF-1 activation and tumor angiogenesis. PLoS ONE. 2012;7(3):e33418-e.

47. De Saedeleer CJ, Copetti T, Porporato PE, Verrax J, Feron O, Sonveaux P. Lactate activates HIF-1 in oxidative but not in Warburg-phenotype human tumor cells. PLoS ONE. 2012;7:10.

48. Végran F, Boidot $R$, Michiels $C$, Sonveaux $P$, Feron O. Lactate influx through the endothelial cell monocarboxylate transporter MCT1 supports an NF-KB/IL-8 pathway that drives tumor angiogenesis. Cancer Res. 2011;71(7):2550-60.

49. Lee DC, Sohn HA, Park Z-Y, Oh S, Kang YK, Lee K-M, et al. A lactate-induced response to hypoxia. Cell. 2015;161(3):595-609.

50. Stern R, Shuster S, Neudecker BA, Fromby B. Lactate stimulates fibroblast expression of hyaluronan and CD44: The Warburg effect revisited. Exp Cell Res. 2002;276(1):24-31

51. Huber V, Camisaschi C, Berzi A, Ferro S, Lugini L, Triulzi T, et al. Cancer acidity: An ultimate frontier of tumor immune escape and a novel target of immunomodulation. Semin Cancer Biol. 2017:43:74-89.

52. Porporato P, Filigheddu N, Pedro JM, Kroemer G, Galluzzi L. Mitochondrial metabolism and cancer. Cell Res. 2018;28(3):265-80.

53. Ashton TM, McKenna WG, Kunz-Schughart LA, Higgins GS. Oxidative phosphorylation as an emerging target in cancer therapy. Clin Cancer Res. 2018:24(11):2482-90.

54. Shen H, Yu M, Tsoli M, Chang C, Joshi S, Liu J, et al. Targeting reduced mitochondrial DNA quantity as a therapeutic approach in pediatric highgrade gliomas. Neurooncology. 2020;22(1):139-51.

55. Griguer C, Oliva C, Gillespie G. Glucose Metabolism Heterogeneity in Human and Mouse Malignant Glioma Cell Lines. J Neuro-Oncol. 2005;74(2):123-33.

56. Duan K, Liu Z-J, Hu S-Q, Huo H-Y, Xu Z-R, Ruan J-F, et al. Lactic acid induces lactate transport and glycolysis/OXPHOS interconversion in glioblastoma. Biochem Biophys Res Commun. 2018:503(2):888-94.

57. Yoshida GJ. Metabolic reprogramming: the emerging concept and associated therapeutic strategies. J Exp Clin Canc Res. 2015;34(1):111-

58. De Luca A, Fiorillo M, Peiris-Pagès M, Ozsvari B, Smith DL, Sanchez-Alvarez R, et al. Mitochondrial biogenesis is required for the anchorage-independent survival and propagation of stem-like cancer cells. Oncotarget. 2015;6(17):14777-95.

59. Zhang M, Rosen JM. Stem cells in the etiology and treatment of cancer. Curr Opin Genet. 2006;16(1):60-4

60. Yoshida GJ, Saya H. Therapeutic strategies targeting cancer stem cells. Cancer Sci. 2016:107:5-11.

61. Viale A, Pettazzoni P, Lyssiotis CA, Ying H, Sánchez N, Marchesini M, et al. Oncogene ablation-resistant pancreatic cancer cells depend on mitochondrial function. Nature. 2014;514(7524):628-32.

62. Vlashi E, Lagadec C, Vergnes L, Matsutani T, Masui K, Poulou M, et al. Metabolic state of glioma stem cells and nontumorigenic cells. Proc Natl Acad Sci U S A. 2011:108(38):16062-7.

63. Hegazy AM, Yamada D, Kobayashi M, Kohno S, Ueno M, Ali MAE, et al. Therapeutic Strategy for Targeting Aggressive Malignant Gliomas by Disrupting Their Energy Balance. J Biol Chem. 2016;291(41):21496-509. 
64. Nakajima EC, Van Houten B. Metabolic symbiosis in cancer: Refocusing the Warburg lens. Mol Carcinog. 2013;52(5):329-37.

65. Jong MR. Inhibition of lactate dehydrogenase to treat epilepsy. N Engl J Med. 2015;373(2):187.

66. Sonveaux P, Vegran F, Schroeder T, Wergin MC, Verrax J, Rabbani ZN, et al. Targeting lactate-fueled respiration selectively kills hypoxic tumor cells in mice. J Clin Invest. 2008;118(12):3930.

67. Froberg KM, Gerhart ZD, Enerson EB, Manivel RC, Guzman-Paz RM, Seacotte $\mathrm{RN}$, et al. Expression of monocarboxylate transporter MCT1 in normal and neoplastic human CNS tissues. Neuroreport. 2001;12(4):761-5.

68. Calabrese C, Poppleton H, Kocak M, Hogg TL, Fuller C, Hamner B, et al. A Perivascular Niche for Brain Tumor Stem Cells. Cancer Cell. 2007;11(1):69-82.

69. Pietras A, Katz Amanda M, Ekström Elin J, Wee B, Halliday John J, Pitter Kenneth L, et al. Osteopontin-CD44 Signaling in the Glioma Perivascular Niche Enhances Cancer Stem Cell Phenotypes and Promotes Aggressive Tumor Growth. Cell Stem Cell. 2014;14(3):357-69.

70. Moeller B, Richardson R, Dewhirst M. Hypoxia and radiotherapy: opportunities for improved outcomes in cancer treatment. Cancer Metastasis Rev. 2007;26(2):241-8.

71. Coates JT, Skwarski M, Higgins GS. Targeting tumour hypoxia: Shifting focus from oxygen supply to demand. Br J Radiol. 2018:92:1093.

72. Phillips RM. Targeting the hypoxic fraction of tumours using hypoxiaactivated prodrugs. Cancer Chemother Pharmacol. 2016;77(3):441.

73. Secomb TW, Hsu R, Ong ET, Gross JF, Dewhirst MW. Analysis of the effects of oxygen supply and demand on hypoxic fraction in tumors. Acta Oncol. 1995;34(3):313-6.

74. Benej M, Hong X, Vibhute S, Scott S, Wu J, Graves E, et al. Papaverine and its derivatives radiosensitize solid tumors by inhibiting mitochondrial metabolism. Proc Natl Acad Sci U S A. 2018;115(42):10756-61.

75. Kim J-w, Gao P, Liu Y-C, Semenza GL, Dang CV. Hypoxia-Inducible Factor 1 and Dysregulated c-Myc Cooperatively Induce Vascular Endothelial Growth Factor and Metabolic Switches Hexokinase 2 and Pyruvate Dehydrogenase Kinase 1. Mol Cell Biol. 2007;27(21):7381.

76. Dang CV, Le A, Gao P. MYC-induced cancer cell energy metabolism and therapeutic opportunities. Clin Cancer Res. 2009;15(21):6479-83.

77. Yoshida GJ. Emerging roles of Myc in stem cell biology and novel tumor therapies. J Exp Clin Canc Res. 2018;37:1.

78. Xie Y, Shi X, Sheng K, Han G, Li W, Zhao Q, et al. PI3K/Akt signaling transduction pathway, erythropoiesis and glycolysis in hypoxia (Review). (phosphoinositide 3-kinase). Mol Med Rep. 2019;19(2):783.

79. Ramanathan A, Schreiber SL. Direct control of mitochondrial function by mTOR. Proc Natl Acad Sci U S A. 2009;106(52):22229-32.

80. Hardie DG. AMP-activated/SNF1 protein kinases: conserved guardians of cellular energy. Nat Rev Mol Cell Biol. 2007;8(10):774.

81. Plews LR, Mohd Yusof DA, Wang EC, Saji EM, Zhang EX, Chen EC-S, et al. A Novel Dual AMPK Activator/mTOR Inhibitor Inhibits Thyroid Cancer Cell Growth. J Clin Endocrinol Metab. 2015;100(5):E748-E56.

82. Sica V, Bravo-San Pedro JM, Stoll G, Kroemer G. Oxidative phosphorylation as a potential therapeutic target for cancer therapy. Int J Cancer. 2020;146(1):10-7.

83. Zannella VE, Dal Pra A, Muaddi H, McKee TD, Stapleton S, Sykes J, et al. Reprogramming metabolism with metformin improves tumor oxygenation and radiotherapy response. Clin Cancer Res. 2013;19(24):6741.

84. Ashton TM, Fokas E, Kunz-Schughart LA, Folkes LK, Anbalagan S, Huether M et al. The anti-malarial atovaquone increases radiosensitivity by alleviating tumour hypoxia. Nat Commun. 2016;7:12308.

85. Fiorillo M, Lamb R, Tanowitz HB, Mutti L, Krstic-Demonacos M, Cappello AR, et al. Repurposing atovaquone: targeting mitochondrial complex III and OXPHOS to eradicate cancer stem cells. Oncotarget. 2016;7(23):34084-99.

86. Tian S, Chen H, Tan W. Targeting mitochondrial respiration as a therapeutic strategy for cervical cancer. Biochem Biophys Res Commun. 2018:499(4): 1019-24.

87. Lv Z, Yan X, Lu L, Su C, He Y. Atovaquone enhances doxorubicin's efficacy via inhibiting mitochondrial respiration and STAT3 in aggressive thyroid cancer. J Bioenerg Biomembr. 2018;50(4):263-70.

88. Chen D, Sun X, Zhang X, Cao J. Targeting mitochondria by anthelmintic drug atovaquone sensitizes renal cell carcinoma to chemotherapy and immunotherapy. J Biochem Mol Toxicol. 2018;32(9):e22195.

89. Ke F, Yu J, Chen W, Si X, Li X, Yang F, et al. The anti-malarial atovaquone selectively increases chemosensitivity in retinoblastoma via mitochondrial dysfunction-dependent oxidative damage and Akt/AMPK/mTOR inhibition. Biochem Biophys Res Commun. 2018;504(2):374-9.
90. Xiang M, Kim H, Ho VT, Walker SR, Bar-Natan M, Anahtar M, et al. Gene expression-based discovery of atovaquone as a STAT3 inhibitor and anticancer agent. Blood. 2016;128(14):1845-53.

91. Takabe H, Warnken ZN, Zhang Y, Davis DA, Smyth HDC, Kuhn JG, et al. A Repurposed Drug for Brain Cancer: Enhanced Atovaquone Amorphous Solid Dispersion by Combining a Spontaneously Emulsifying Component with a Polymer Carrier. Pharmaceutics. 2018;10:2.

92. DynaMed. Atovaquone Ipswich MA. EBSCO Information Services; 2020 [cited 202016 April]. Available from: https://www-dynamed-com.ezproxy1.library. usyd.edu.au/drug-monograph/atovaquone.

93. DynaMed. Ivermectin Ipswich MA. EBSCO Information Services; 2019 [cited 202015 April]. Available from: https://www-dynamed-com.ezproxy1.library. usyd.edu.au/drug-monograph/ivermectin.

94. Song D, Liang H, Qu B, Li Y, Liu J, Zhang Y, et al. Ivermectin inhibits the growth of glioma cells by inducing cell cycle arrest and apoptosis in vitro and in vivo. J Cell Biochem. 2019;120(1):622-33.

95. Zhu M, Li Y, Zhou Z. Antibiotic ivermectin preferentially targets renal cancer through inducing mitochondrial dysfunction and oxidative damage. Biochem Biophys Res Commun. 2017;492(3):373-8.

96. Wang J, Xu Y, Wan H, Hu J. Antibiotic ivermectin selectively induces apoptosis in chronic myeloid leukemia through inducing mitochondrial dysfunction and oxidative stress. Biochem Biophys Res Commun. 2018; 497(1):241-7.

97. Liu Y, Fang S, Sun Q, Liu B. Anthelmintic drug ivermectin inhibits angiogenesis, growth and survival of glioblastoma through inducing mitochondrial dysfunction and oxidative stress. Biochem Biophys Res Commun. 2016;480(3):415-21.

98. Dou Q, Chen H-N, Wang K, Yuan K, Lei Y, Li K, et al. Ivermectin Induces Cytostatic Autophagy by Blocking the PAK1/Akt Axis in Breast Cancer. Cancer Res. 2016;76(15):4457-69.

99. Hashimoto H, Messerli SM, Sudo T, Maruta H. Ivermectin inactivates the kinase PAK1 and blocks the PAK1-dependent growth of human ovarian cancer and NF2 tumor cell lines. Drug Discov Ther. 2009;3(6):243-6.

100. Chen L, Bi S, Wei Q, Zhao Z, Wang C, Xie S. Ivermectin suppresses tumour growth and metastasis through degradation of PAK1 in oesophageal squamous cell carcinoma. J Cell Mol Med. 2020;24(9):5387-401.

101. Deng F, Xu Q, Long J, Xie H. Suppressing. ROS-TFE3-dependent autophagy enhances ivermectin-induced apoptosis in human melanoma cells. J Cell Biochem. 2019;120(2):1702-15.

102. Sharmeen S, Skrtic M, Sukhai M, Hurren R, Gronda M, Wang X, et al. The antiparasitic agent ivermectin induces chloride-dependent membrane hyperpolarization and cell death in leukemia cells. Blood. 2010;116(18):3593603.

103. Melotti A, Mas C, Kuciak M, Lorente-Trigos A, Borges I, Ruiz I, Altaba A. The river blindness drug Ivermectin and related macrocyclic lactones inhibit WNT - TCF pathway responses in human cancer. EMBO Mol Med. 2014; 6(10):1263-78

104. Zhang P, Zhang Y, Liu K, Liu B, Xu W, Gao J, et al. Ivermectin induces cell cycle arrest and apoptosis of HeLa cells via mitochondrial pathway. Cell Prolif. 2019;52(2): n/a-n/a.

105. Yan K-H, Yao C-J, Hsiao C-H, Lin K-H, Lin Y-W, Wen Y-C, et al. Mefloquine exerts anticancer activity in prostate cancer cells via ROS-mediated modulation of Akt, ERK, JNK and AMPK signaling. Oncology letters. 2013; 5(5):1541-5

106. Liu Y, Chen S, Xue R, Zhao J, Di M. Mefloquine effectively targets gastric cancer cells through phosphatase-dependent inhibition of PI3K/ Akt/mTOR signaling pathway. Biochem Biophys Res Commun. 2016; 470(2):350-5.

107. Li H, Jiao S, Li X, Banu H, Hamal S, Wang X. Therapeutic effects of antibiotic drug mefloquine against cervical cancer through impairing mitochondrial function and inhibiting mTOR pathway. Can J Physiol Pharmacol. 2017;95(1): 43-50.

108. Sharma N, Thomas S, Golden EB, Hofman FM, Chen TC, Petasis NA, et al. Inhibition of autophagy and induction of breast cancer cell death by mefloquine, an antimalarial agent. Cancer Lett. 2012;326(2):143-54.

109. Li Y-H, Yang S-L, Zhang G-F, Wu J-C, Gong L-L, Lin R-X. Mefloquine targets $\beta$-catenin pathway and thus can play a role in the treatment of liver cancer. Microb Pathog. 2018;118:357-60.

110. Xu X, Wang J, Han K, Li S, Xu F, Yang Y. Antimalarial drug mefloquine inhibits nuclear factor kappa B signaling and induces apoptosis in colorectal cancer cells. Cancer Sci. 2018;109(4):1220-9. 
111. Takeda M, Koseki J, Takahashi H, Miyoshi N, Nishida N, Nishimura J, et al. Disruption of Endolysosomal RAB5/7 Efficiently Eliminates Colorectal Cancer Stem Cells. Cancer Res. 2019;79(7):1426.

112. Das S, Dielschneider R, Chanas-Larue A, Johnston JB, Gibson SB. Antimalarial drugs trigger lysosome-mediated cell death in chronic lymphocytic leukemia (CLL) cells. Leuk Res. 2018;70:79-86.

113. Sukhai MA, Prabha S, Hurren R, Rutledge AC, Lee AY, Sriskanthadevan S, et al. Lysosomal disruption preferentially targets acute myeloid leukemia cells and progenitors. J Clin Invest. 2013;123(1):315-28.

114. Geng Y, Kohli L, Klocke BJ, Roth KA. Chloroquine-induced autophagic vacuole accumulation and cell death in glioma cells is p53 independent. Neurooncology. 2010;12(5):473-81.

115. Lea M, Kim H, Desbordes C. Effects of Biguanides on Growth and Glycolysis of Bladder and Colon Cancer Cells. Anticancer Res. 2018;38(9):5003.

116. Oien DB, Pathoulas CL, Ray U, Thirusangu P, Kalogera E, Shridhar V. Repurposing quinacrine for treatment-refractory cancer. Semin Cancer Biol. 2019.

117. Preet R, Mohapatra P, Mohanty S, Sahu SK, Choudhuri T, Wyatt MD, et al. Quinacrine has anticancer activity in breast cancer cells through inhibition of topoisomerase activity. Int J Cancer. 2012;130(7):1660-70.

118. Mohapatra P, Preet R, Das D, Satapathy SR, Choudhuri T, Wyatt MD, et al. Quinacrine-mediated autophagy and apoptosis in colon cancer cells is through a p53-and p21-dependent mechanism. Oncol Res. 2012; 20(2-3):81-91

119. Khurana A, Roy D, Kalogera E, Mondal S, Wen X, He X, et al. Quinacrine promotes autophagic cell death and chemosensitivity in ovarian cancer and attenuates tumor growth. Oncotarget. 2015;6(34):36354.

120. Yang S, Sheng L, Xu K, Wang Y, Zhu H, Zhang $P$, et al. Anticancer effect of quinacrine on diffuse large Bcell lymphoma via inhibition of MSI2NUMB signaling pathway. Mol Med Rep. 2018;17(1):522-30.

121. Gurova K, Hill J, Guo C, Prokvolit A. Small molecules that reactivate p53 in renal cell carcinoma reveal a NF-B-dependent mechanism of p53 suppression in tumors. Proc Natl Acad Sci U S A. 2005;102(48):17448-53.

122. Kim M, Blum A, Haslinger M, Donahue M, Fisher D, Skitzki J, et al. Quinacrine for extremity melanoma in a mouse model of isolated limb perfusion (ILP). Surg Today. 2015;45(3):355-62.

123. Changchien J-J, Chen Y-J, Huang C-H, Cheng T-L, Lin S-R, Chang L-S. Quinacrine induces apoptosis in human leukemia K562 cells via p38 MAPKelicited BCL2 down-regulation and suppression of ERK/c-Jun-mediated BCL2L1 expression. Toxicol Appl Pharmacol. 2015;284(1):33-41.

124. Wu X, Wang Y, Wang H, Wang Q, Wang L, Miao J, et al. Quinacrine Inhibits Cell Growth and Induces Apoptosis in Human Gastric Cancer Cell Line SGC7901. Curr Ther Res Clin Exp. 2012;73(1-2):52-64.

125. Gallant J-N, Allen JE, Smith CD, Dicker DT, Wang W, Dolloff NG, et al. Quinacrine synergizes with 5-fluorouracil and other therapies in colorectal cancer. Cancer Biol Ther. 2011;12(3):239-51.

126. Dermawan JKT, Gurova K, Pink J, Dowlati A, De S, Narla G, et al. Quinacrine overcomes resistance to erlotinib by inhibiting FACT, NF-kB, and cell-cycle progression in non-small cell lung cancer. Mol Cancer Ther. 2014;13(9):2203-14.

127. Matteoni S, Abbruzzese C, Matarrese P, De Luca G, Mileo AM, Miccadei S, et al. The kinase inhibitor SI113 induces autophagy and synergizes with quinacrine in hindering the growth of human glioblastoma multiforme cells. J Exp Clin Canc Res. 2019;38(1):202.

128. Baggish AL, Hill DR. Antiparasitic agent atovaquone. Antimicrob Agents Chemother. 2002;46(5):1163-73.

129. Frank DA. STAT3 as a central mediator of neoplastic cellular transformation. Cancer Lett. 2007;251(2):199-210.

130. Juarez M, Schcolnik-Cabrera A, Duenas-Gonzalez A. The multitargeted drug ivermectin: from an antiparasitic agent to a repositioned cancer drug. Am J Cancer Res. 2018;8(2):317-31.

131. Bai SH, Ogbourne S. Eco-toxicological effects of the avermectin family with a focus on abamectin and ivermectin. Chemosphere. 2016;154:204-14.

132. Edwards G. Ivermectin: does P-glycoprotein play a role in neurotoxicity? Filaria J. 2003;2(Suppl 1):8.

133. Didier $A$, Loor $F$. The abamectin derivative ivermectin is a potent $P$ glycoprotein inhibitor. Anticancer Drugs. 1996;7(7):745-51.

134. Gao A, Wang X, Xiang W, Liang H, Gao J, Yan Y. Reversal of P-glycoproteinmediated multidrug resistance in vitro by doramectin and nemadectin. $J$ Pharm Pharmacol. 2010;62(3):393-9.

135. Trenholme CM, Williams RL, Desjardins RE, Frischer H, Carson PE, Rieckmann $\mathrm{KH}$, et al. Mefloquine (WR 142,490) in the treatment of human malaria Science. 1975;190(4216):792-4.
136. Wilson W, Xiao-Chen B, Brad ES, Tony T, Alan B, Jennifer KT, et al. Mefloquine targets the Plasmodium falciparum $80 \mathrm{~S}$ ribosome to inhibit protein synthesis. Nat Microbiol. 2017;2:6.

137. Tapodi A, Debreceni B, Hanto K, Bognar Z, Wittmann I, Gallyas F, et al. Pivotal role of Akt activation in mitochondrial protection and cell survival by poly (ADP-ribose) polymerase-1 inhibition in oxidative stress. J Biol Chem. 2005;280(42):35767-75

138. Radloff P, Philipps J, Nkeyi M, Hutchinson D, Kremsner P. Atovaquone and proguanil for Plasmodium falciparum malaria. Lancet. 1996;347(9014):1511-4

139. McKeage K, Scott L. Atovaquone/Proguanil. Drugs. 2003;63(6):597-623.

140. Bridges HR, Jones AJY, Pollak MN, Hirst J. Effects of metformin and other biguanides on oxidative phosphorylation in mitochondria. Biochem J. 2014; 462(3):475-87.

141. Zipper J, Dabancens A, Guerrero A, Trujillo V. Quinacrine revised. Hum Reprod Update. 1995;1(4):324-42.

142. Canete R, Escobedo AA, Gonzalez ME, Almirall P. Randomized clinical study of five days apostrophe therapy with mebendazole compared to quinacrine in the treatment of symptomatic giardiasis in children. World J Gastroenterol. 2006;12(39):6366-70.

143. Koul PA, Wahid A, Bhat MH, Wani JI, Sofi BA. Mepacrine therapy in niclosamide resistant taeniasis. J Assoc Physicians India. 2000;48(4):402

144. Toubi E, Kessel A, Rosner I, Rozenbaum M, Paran D, Shoenfeld Y. The reduction of serum B-lymphocyte activating factor levels following quinacrine add-on therapy in systemic lupus erythematosus. Scand J Immunol. 2006;63(4):299-303.

145. Rynes RI. Antimalarial drugs in the treatment of rheumatological diseases. Rheumatology. 1997;36(7):799-805.

146. Taylor SA, Hooton NS, Macarthur AM. Quinacrine in the management of malignant pleural effusion. Br J Surg. 1977;64(1):52-3.

147. Larrieu AJ, Tyers GFO, Williams EH, O'Neill MJ, Derrick JR. Intrapleural Instillation of Quinacrine for Treatment of Recurrent Spontaneous Pneumothorax. Ann Thorac Surg. 1979;28(2):146-50.

148. Hieu DT, Vinh DQ, Tan DN, Tan TT, Nguyet PT, Than P. 31781 cases of nonsurgical female sterilisation with quinacrine pellets in Vietnam. The Lancet. 1993:342(8865):213-7.

149. Doh-Ura K, Iwaki T, Caughey B. Lysosomotropic agents and cysteine protease inhibitors inhibit scrapie-associated prion protein accumulation. J Virol. 2000;74(10):4894-7

150. Ehsanian R, Van Waes C, Feller SM. Beyond DNA binding - a review of the potential mechanisms mediating quinacrine's therapeutic activities in parasitic infections, inflammation, and cancers. Cell Commun Signal. 2011;9:1.

151. Reyes AS, Herrera AL, Ostrosky AP, Sotelo AJ. Quinacrine Enhances Carmustine Therapy of Experimental Rat Glioma. Neurosurgery. 2001:49(4):969-73.

152. Jani T, Devecchio J, Mazumdar T, Agyeman A, Houghton J. Inhibition of NFkappa B Signaling by Quinacrine Is Cytotoxic to Human Colon Carcinoma Cell Lines and Is Synergistic in Combination with Tumor Necrosis Factorrelated Apoptosis-inducing Ligand (TRAIL) or Oxaliplatin. J Biol Chem. 2010; 285(25):19162-72

153. Wang Y, Bi Q, Dong L, Li X, Ge X, Zhang X, et al. Quinacrine enhances cisplatininduced cytotoxicity in four cancer cell lines. Chemotherapy. 2010;56(2):127.

154. Abdulghani J, Gokare P, Gallant J-N, Dicker D, Whitcomb T, Cooper T, et al. Sorafenib and Quinacrine Target Anti-Apoptotic Protein MCL1: A Poor Prognostic Marker in Anaplastic Thyroid Cancer (ATC). Clin Cancer Res. 2016; 22(24):6192-203.

155. Kalogera E, Roy D, Khurana A, Mondal S, Weaver AL, He X, et al. Quinacrine in endometrial cancer: Repurposing an old antimalarial drug. Gynecol Oncol. 2017:146(1):187-95.

156. Wang Y, Ying $X$, Xu HL, Yan HL, Li X, Tang H. The functional curcumin liposomes induce apoptosis in C6 glioblastoma cells and C6 glioblastoma stem cells in vitro and in animals. Int J Nanomedicine. 2017;12:1369-84.

157. Kimura T, Takabatake Y, Takahashi A, Isaka Y. Chloroquine in Cancer Therapy: A Double-Edged Sword of Autophagy. Cancer Res. 2013;73(1):3-7.

158. Yoshida GJ. Therapeutic strategies of drug repositioning targeting autophagy to induce cancer cell death: from pathophysiology to treatment. J Hematol Oncol. 2017:10:1.

159. Laurence Z, Jonathan MP, Romain D, Mark JS, Guido K. Mouse models in oncoimmunology. Nat Rev Cancer. 2016;16:12.

\section{Publisher's Note}

Springer Nature remains neutral with regard to jurisdictional claims in published maps and institutional affiliations. 